\title{
Circulation characteristics in three eddy-permitting models of the North Atlantic
}

\author{
Jürgen Willebrand a,*, Bernard Barnier ${ }^{\mathrm{b}}$, Claus Böning a, Christian Dieterich ${ }^{1, a}$, \\ Peter D. Killworth ${ }^{\mathrm{c}}$, Christian Le Provost $2, \mathrm{~b}$, Yanli Jia ${ }^{\mathrm{c}}$, Jean-Marc Molines ${ }^{\mathrm{b}}$, \\ Adrian L. New ${ }^{\mathrm{c}}$ \\ a Institut für Meereskunde, Universität Kiel, Kiel, Germany \\ b Laboratoire des Ecoulements Géophysiques et Industriels, Grenoble, France \\ c Southampton Oceanography Centre, Southampton, UK
}

\begin{abstract}
A systematic intercomparison of three realistic eddy-permitting models of the North Atlantic circulation has been performed. The models use different concepts for the discretization of the vertical coordinate, namely geopotential levels, isopycnal layers, terrain-following (sigma) coordinates, respectively. Although these models were integrated under nearly identical conditions, the resulting large-scale model circulations show substantial differences. The results demonstrate that the large-scale thermohaline circulation is very sensitive to the model representation of certain localised processes, in particular to the amount and water mass properties of the overflow across the Greenland-Scotland region, to the amount of mixing within a few hundred kilometers south of the sills, and to several other processes at small or sub-grid scales. The different behaviour of the three models can to a large extent be explained as a consequence of the different model representation of these processes. (c) 2001 Elsevier Science Ltd. All rights reserved.
\end{abstract}

\section{Contents}

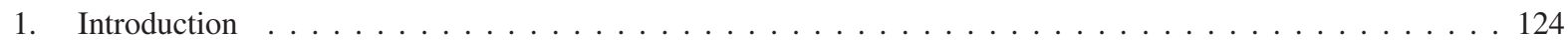

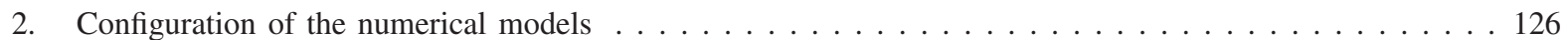

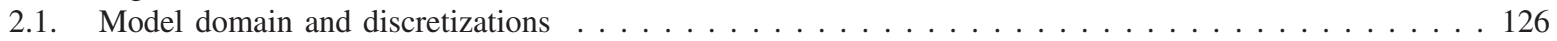

2.1.1. Horizontal grid . . . . . . . . . . . . . . . . . . . . . . . . . . . . . . . 126

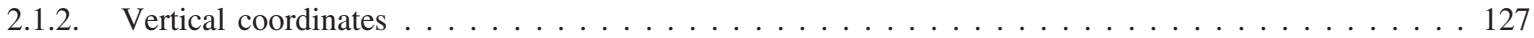

* Corresponding author. Tel.: +49-431-597-3800; fax: +49-431-597-565876.

E-mail address: jwillebrand@ifm.uni-kiel.de (J. Willebrand).

${ }^{1}$ Now at: Alfred-Wegener Institut, Bremerhaven, Germany

${ }^{2}$ Now at: Laboratoire d'Etudes en Géophysique et Oceanographie Spatiale, Toulouse, France 


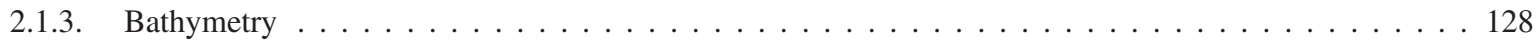

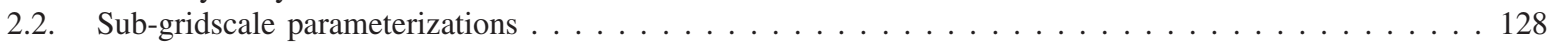

2.2.1. Lateral mixing . . . . . . . . . . . . . . . . . . . . . . . . . . . . . . . 128

2.2.2. Vertical mixing . . . . . . . . . . . . . . . . . . . . . . . . . . . . 129

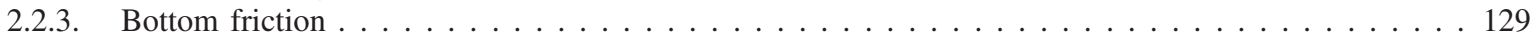

2.2.4. Mixed layer turbulence . . . . . . . . . . . . . . . . . . . . . . . . . . . 130

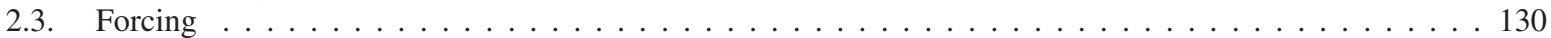

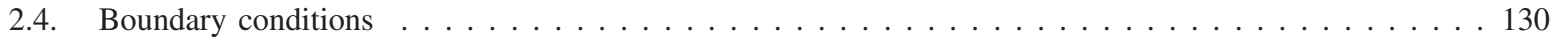

2.5. Initialization and integration of main experiment $\ldots \ldots \ldots \ldots \ldots \ldots \ldots \ldots \ldots \ldots \ldots \ldots \ldots$

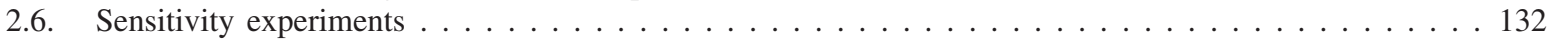

3. Results . . . . . . . . . . . . . . . . . . . . . . . . . 132

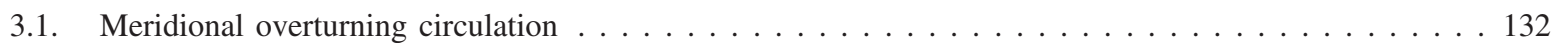

3.2. Thermohaline transport in the subtropical gyre . . . . . . . . . . . . . . . . . . . . . . 140

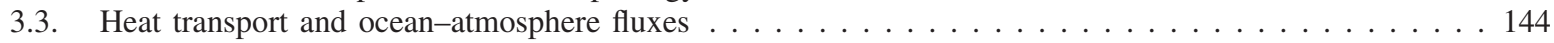

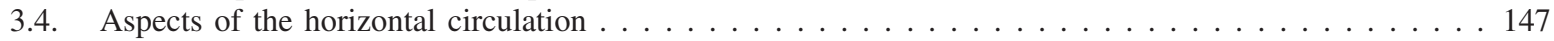

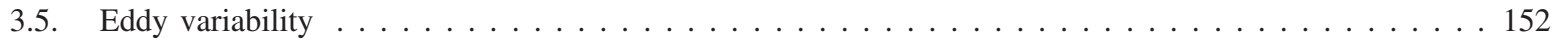

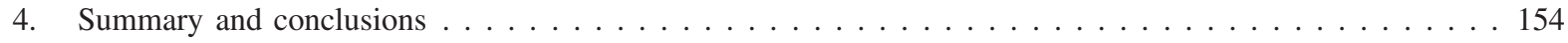

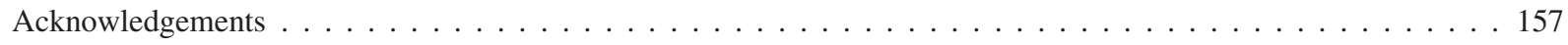

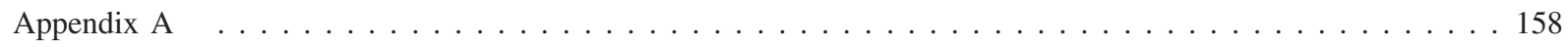

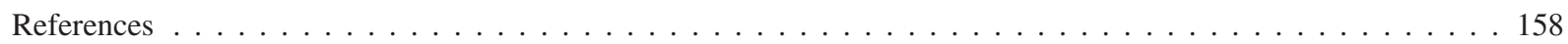

\section{Introduction}

The large-scale current systems in the North Atlantic are characterised by a rich spectrum of variability, as demonstrated by a number of observational programmes. Even with modern techniques such as ship-based ADCPs, remotely-tracked drifting buoys or long-term moorings, the limitations of sea-going data acquisition are such that only very little of this variability can be sampled directly at sea. Only satellite observations provide essentially global coverage of synoptic data, but they are restricted to the ocean surface. Accordingly, a quantitative determination of the circulation, let alone an understanding of its dynamics and interactions, cannot be obtained through field studies alone; numerical models are necessary both to help with the interpretation of the data, and to build an understanding of ocean dynamics.

Studies of ocean circulation by means of numerical models have proliferated in recent years, fueled both by the recognition of an increasing realism of the model solutions and by the increases in computing power (see, e.g., McWilliams, 1996, for a review of the history and solution behaviour of ocean circulation models). However, the vast range of time and space scales excited in the ocean continues to present a formidable challenge to ocean modelling. Though it has become possible in recent years to incorporate a significant fraction of the mesoscale eddy spectrum into models of global coverage (e.g., Stammer, Tokmakian, Semtner \& Wunsch, 1996), the integration period of these models has to be limited to a few decades, and the solutions continue to be dependent on parameterisations of important, small-scale physical processes. 
A suite of sensitivity studies into the effect of different physical processes and model parameterisations in the context of a high-resolution North Atlantic model has been performed under the US-German 'Community Modelling Effort' (CME) in support of the World Ocean Circulation Experiment (for a review see Böning \& Bryan, 1996). The basic model configuration was that of an Atlantic basin between $15^{\circ} \mathrm{S}$ and $65^{\circ} \mathrm{N}$, with closed walls at the northern and southern boundaries. A focus of the $\mathrm{CME}$ analyses was on the dynamics of the current variability in the tropical and subtropical Atlantic, where the model solutions began to reproduce many observed features in a realistic way (e.g., Didden \& Schott, 1991; Schott \& Molinari, 1996). There were considerable problems, on the other hand, at higher latitudes. Perhaps the most glaring deficit the CME shared with a number of other model studies concerns the failure to simulate the observed current structure (Redler \& Böning, 1997) and eddy variability (Treguier, 1992) in the northeastern parts of the basin. Sensitivity experiments with different versions of open boundary conditions emphasised the need for an improved representation of the water exchange with the Norwegian Sea (Redler \& Böning, 1997). The numerical representation of the outflow of deep water across the Greenland-Iceland-Scotland ridge in turn was found to be of decisive influence on important, basin-scale aspects of the circulation; in particular, the density of the outflow prescribed by the northern boundary condition in the CME was a key factor determining the structure and strength of the meridional overturning circulation with its associated northward transport of heat (Döscher, Böning \& Herrmann, 1994; Holland \& Bryan, 1994).

To date, a majority of such simulations have been produced using one standard type of ocean model, i.e., the model developed at GFDL (Bryan, 1969; Cox, 1984; Pacanowski, 1995) which is constructed such that coordinate surfaces coincide with geopotential levels, thus accounting for the overriding magnitude of the gravity force in the equations of motion. The geopotential level formulation has been a convenient and versatile concept for general purpose models, it has been used equally well to simulate e.g. the wind-driven or thermohaline circulation, storm surges and the circulation in shelf seas, small-scale convection, to name but a few. However, the staircase representation of topography results in the model being less well suited to simulate topographically controlled flows (Roberts, Marsh, New \& Wood, 1996; Beckmann \& Döscher, 1997). Also, the dependence of model solutions on the parameterisation of sub-grid-scale mixing (e.g., Bryan, 1987) emphasises the need to critically assess the potential of alternative model formulations.

New model developments have in particular focussed on a different representation of the vertical coordinate. In models with an isopycnic coordinate system (e.g. Bleck, Rooth, Hu \& Smith, 1992; Oberhuber, 1993), the flow along and the thickness of individual (and homogeneous) layers of fluid is predicted. Such a representation is optimally suited to represent water mass transports that occur along isopycnal surfaces, a traditional concept in oceanography which has ample support from observations. In the terrain-following coordinate system (e.g. Haidvogel, Wilkin \& Young, 1991) the model coordinates smoothly conform to the irregular bottom, which is most suitable when topographic influence is the dominant factor, as borne out by meteorological experience with terrain-following coordinates.

The main objective of this investigation is to obtain an improved understanding of the dependence of the simulated North Atlantic circulation, including its variability on synoptic and seasonal time scales, on various aspects of the model formulation. In order to achieve this, we have performed a systematic intercomparison of three models of the North Atlantic circulation. The models use different concepts for the discretization of the vertical coordinate, namely i) geopoten- 
tial levels (Cartesian z-coordinates), ii) isopycnal layers, and iii) terrain-following coordinates. The focus will be on basin-wide aspects of the simulations, and in particular on the thermohaline circulation.

Any model intercomparison has to take into account a possible, but often unknown dependency of each model on a considerable number of model choices: details of the model topography, boundary conditions or mixing parameterisations can all have significant impact on the behaviour of the basin-scale circulation. Ideally, a comparison of different numerical models with regard to their ability to reproduce observed features of the ocean should not be based on single realisations of these models, with a given set of parameters, but between sets of experiments that give an idea of their parameter dependencies. Since this is far beyond present computational resources, we need to take into account, as far as possible, the information available from sensitivity studies with similar model configurations. These have, in particular, been carried out under the CME framework where a suite of model versions differing in horizontal resolution, friction, wind forcing and thermohaline boundary conditions were examined, and may be utilised to assess the solution of the geopotential level model in this study. Some experience also existed with previous North Atlantic applications of the Miami isopycnic model for the North Atlantic, including comparisons between non-eddy resolving versions of that model with similar versions of the GFDL model (Marsh, Roberts, Wood \& New, 1996; Roberts et al., 1996). Less experience existed prior to this study with basin-scale eddy-permitting models in terrain-following coordinates; however, a model realization for the Atlantic Ocean using a medium resolution version of the Princeton Ocean Model has recently been described by Ezer and Mellor (1997).

\section{Configuration of the numerical models}

Three primitive equation models of the North Atlantic which are based on different concepts for the discretization of the vertical coordinate have been set up as closely as possible for a systematic model intercomparison. The geopotential level (Cartesian z-coordinate) model is originally based on the GFDL-MOM code (Cox, 1984), the isopycnal coordinate model is based on the MICOM code (Bleck et al., 1992), and the depth-following sigma-coordinate model is based on the SPEM code (Haidvogel et al., 1991). The models will henceforth be referred to as LEVEL, ISOPYCNIC and SIGMA, respectively. We have attempted, as far as possible, to have identical configurations in the three models, in order to be able to understand differences in model behaviour in terms of as few parameters as possible. In the remainder of this section the principal elements of the model configuration are described; further details can be found in a technical report (Dynamo Group, 1997, henceforth D97).

\subsection{Model domain and discretizations}

\subsubsection{Horizontal grid}

The models cover a horizontal domain from $20^{\circ} \mathrm{S}$ to $70^{\circ} \mathrm{N}$, and $100^{\circ} \mathrm{W}$ to $16^{\circ} \mathrm{E}$ which is represented by a horizontal grid of resolution $\Delta \lambda=1 / 3^{\circ}$ in longitude $\lambda$ and $\Delta \varphi=1 / 3^{\circ} \cos \varphi$ in latitude $\varphi$. The resolution of the locally isotropic grid thus varies from $37 \mathrm{~km}$ at the equator to $13 \mathrm{~km}$ at $70^{\circ} \mathrm{N}$, and accounts at least partially for the smaller scales of motion at high latitudes. Domain 
and resolution in the three models are almost identical, except for very small differences caused by differences in the grid structure, and except for one sensitivity experiment with SIGMA (see below). Five islands are included, namely Iceland, Ireland, Mainland Great Britain, Cuba and Hispaniola. The model domain for LEVEL is displayed in Fig. 1.

\subsubsection{Vertical coordinates}

The vertical discretization constitutes the principal difference between the three models and has a strong impact on the representation of topography.

LEVEL is based on 30 geopotential levels. The grid spacing increases from $35 \mathrm{~m}$ at the sea surface to $250 \mathrm{~m}$ below $1000 \mathrm{~m}$ depth, and is identical to that of the CME model (e.g. Döscher et al., 1994); depths of the vertical levels are given in the Appendix A. The bathymetry is represented as step-like on these levels, with a minimum depth of $72 \mathrm{~m}$, resolved by 2 levels, and a maximum depth of $5500 \mathrm{~m}$, yielding the center of the deepest gridcell at $5375 \mathrm{~m}$.

ISOPYCNIC uses a vertical coordinate system with 19 isopycnal layers of constant potential density $\sigma_{\theta}$, varying from 24.70 to 28.12 (see Appendix A), and a mixed layer of arbitrary density. These values are chosen to represent water masses and thermocline structure as closely as possible. The model has a thermodynamic state equation which is cubic in temperature and linear in salinity, and which does not include dynamical effects arising from the compressibility of sea water.

SIGMA is based on a vertical coordinate following the bathymetry according to $\sigma=f(z / H(x, y))$, where $x, y, z$ are geopotential coordinates and $H(x, y)$ is the local depth of the fluid. Following Song and Haidvogel (1994), a non-linear function for $f(z / H(x, y))$ was chosen, with 20 equidistant $\sigma$-levels so that increased resolution near the surface is obtained (see Appendix A).

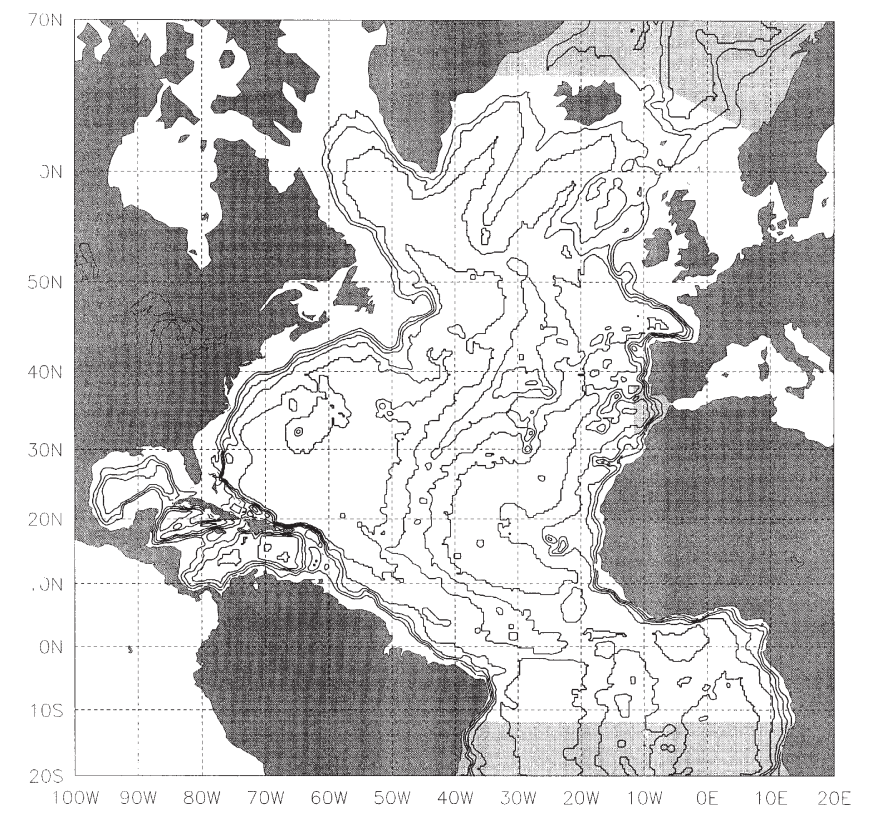

Fig. 1. Domain and topography for the three models (exact for LEVEL, approximate for ISOPYCNIC and SIGMA). The restoring zones off Gibraltar and at the northern and southern boundaries are shaded. Note that at the southern boundary, restoring is applied only for ISOPYCNIC and SIGMA models whereas LEVEL has an open boundary here. 


\subsubsection{Bathymetry}

The bathymetry for the models is derived from the 5' ETOPOS database by the National Geophysical Data Center. However, it has been unavoidably necessary to add a certain amount of subjective modifications, because straightforward filtering mechanisms lead to unsatisfactory descriptions of sill depths and cross-sections of narrow straits in key regions.

According to their respective coordinate systems, all three models use a slightly different topography. For LEVEL, a simple second order Shapiro filter was applied to the data interpolated onto the model's horizontal grid to remove the noise on the gridscale. For ISOPYCNIC, a simple interpolation onto the model grid by taking the median of all bathymetric data within each grid box, without additional smoothing, was performed. The minimum depth of the ocean was set to $75 \mathrm{~m}$, similar to LEVEL. In SIGMA, a comparatively strong smoothing of the bathymetry is required to match a criterion that assures minimal errors of the discrete pressure gradient over steep topography, and also guarantees convergence for the iterative solution of the barotropic vorticity equation (see Barnier, Marchesiello, de Miranda, Molines \& Coulibaly, 1998). The minimum depth is set to $200 \mathrm{~m}$ to limit the constraint on the time-step introduced by the convergence of the 20 levels onto shallow areas. Finally, in LEVEL and SIGMA the topography in several key passages has been widened, in order to allow for advective transports down to the original sill depth (cf. Fig. 3 below).

\subsection{Sub-gridscale parameterizations}

All three models are eddy-resolving (more precisely eddy-permitting), and thus the transport and mixing by mesoscale eddies is explicitly included, at least to a certain extent. The subgridscale parameterisation must therefore primarily describe transports from sub-mesoscale motions. In addition, some mixing of momentum and tracers is also required to prevent numerical instability.

\subsubsection{Lateral mixing}

Both LEVEL and SIGMA use a biharmonic mixing formulation for lateral friction and diffusion. The motivation for this choice is to move the dissipation which is required for numerical stability towards smaller scales compared to Fickian diffusion. In both models, the transports act along horizontal (geopotential) surfaces, which is a natural choice for LEVEL but requires a rotation of the mixing tensor for SIGMA. The biharmonic coefficients vary with the third power of the grid spacing, i.e. according to

$$
B=B_{\text {eq }} \cos ^{3} \varphi
$$

where $B_{\mathrm{eq}}$ denotes the equatorial value. In this way, Peclet and Reynolds numbers at grid scale are independent of latitude for a fixed advection velocity.

ISOPYCNIC uses a Fickian law for isopycnal exchange of momentum, and for the isopycnal diffusion of both layer thickness and tracers. All coefficients are proportional to the grid spacing, i.e.

$$
A=A_{\text {eq }} \cos \varphi
$$

so that again the grid Peclet number is independent of latitude. Following Smagorinsky (1963) 
and Bleck et al. (1992), the coefficient of momentum exchange is formulated as $A=\max \left(A_{1}, A_{2} \gamma\right.$ $\cos \varphi) \cos \varphi$ with the parameters $A_{1}=185 \mathrm{~m}^{2} / \mathrm{s}$ and $A_{2}=4.97 \cdot 10^{4} \mathrm{~m}^{2} / \mathrm{s}$. Here $\gamma$ is defined as

$$
\gamma=\frac{1}{2 \Omega}\left[\left(u_{x}-v_{y}\right)^{2}+\left(v_{x}-u_{y}\right)^{2}\right]^{1 / 2}
$$

in a shorthand Cartesian notation, and $\Omega$ is the earth's rotation rate. $\gamma$ is a dimensionless measure of horizontal shear which has the order of magnitude of a Rossby number. The shear term is effective in regions where $\gamma \cos \varphi>3.7 \cdot 10^{-3}$.

The equatorial values of all mixing parameters are given in Table 1. For horizontal/isopycnal diffusion and friction, the grid Peclet/Reynolds numbers for a given advection velocity are identical in all three models (with the possible exception of the shear term in ISOPYCNIC), and are unity for an advection velocity of $0.5 \mathrm{~cm} / \mathrm{s}$.

\subsubsection{Vertical mixing}

Vertical mixing of momentum in LEVEL and SIGMA is described by harmonic diffusion, with a constant coefficient of $10^{-3} \mathrm{~m}^{2} / \mathrm{s}$. There is no frictional exchange of momentum between layers in ISOPYCNIC.

Diapycnal mixing of temperature and salinity controls the long-term behaviour of the thermohaline circulation but is less crucial for the shorter time scales considered in this study. All three models have the mixing scheme suggested by Gargett (1984), with a diapycnal (vertical) diffusion coefficient according to

$$
K_{v}=a_{0} / N
$$

where $N$ is the local buoyancy frequency and $a_{0}=10^{-7} \mathrm{~m}^{2} / \mathrm{s}^{2}$ (Ledwell, Watson \& Law, 1998). In the case of static instability, effectively a convective adjustment between unstable levels occurs within one timestep. In LEVEL and SIGMA this adjustment is achieved by setting the mixing coefficient to a finite but very large value $\left(1 \mathrm{~m}^{2} \mathrm{~s}^{-2}\right)$ about 4 orders of magnitude larger than typical values in stable situations. Note that in ISOPYCNIC convective adjustment can only occur between the surface mixed layer and the layer immediately below, and static instability elsewhere is precluded through the choice of the coordinate system.

\subsubsection{Bottom friction}

Bottom stress in all three models is parameterised in terms of the horizontal velocity $u$ according to

Table 1

Values for lateral coefficients at the equator in the three models

\begin{tabular}{lll}
\hline & LEVEL and SIGMA $\left(\mathrm{m}^{4} \mathrm{~s}^{-1}\right)$ & ISOPYCNIC $\left(\mathrm{m}^{2} \mathrm{~s}^{-1}\right)$ \\
\hline thickness diffusion & & 37 \\
horizontal tracer diffusion & $2.5 \cdot 10^{11}$ & - \\
isopycnal tracer diffusion & - & 185 \\
horizontal exchange of momentum & $2.5 \cdot 10^{11}$ & - \\
isopycnal exchange of momentum & - & $\geq 185$ \\
\hline
\end{tabular}




$$
F=c_{\mathrm{d}} u \sqrt{u^{2}+u_{0}^{2}}
$$

with a drag coefficient $c_{\mathrm{d}}=1.2 \cdot 10^{-3}$, and $u_{0}=5 \mathrm{~cm} / \mathrm{s}$ representing the effect of residual tidal currents in a simplified way.

\subsubsection{Mixed layer turbulence}

The turbulence in the mixed layer is not explicitly accounted for in LEVEL and SIGMA, except in one sensitivity experiment with LEVEL (see below). The minimum depth of the well-mixed layer is the uppermost grid cell $(35 \mathrm{~m})$ in LEVEL, and $50 \mathrm{~m}$ in SIGMA. Deeper mixed layers can be obtained as a result of convective adjustment as a result of cooling and/or evaporation, but not through wind-induced mixing.

The formulation in ISOPYCNIC is different; it has a mixed layer model based on Kraus and Turner (1967) which also accounts for wind-induced deepening of the mixed layer. For a description see Bleck, Hanson, Hu and Kraus (1989) and Bleck et al. (1992). One important aspect of the mixed layer formulation in ISOPYCNIC is that the velocity within the mixed layer is always uniform with depth whereas in LEVEL and SIGMA a current shear may persist through the mixed layer. In regions of deep mixing, this difference can lead to weaker near-surface currents in ISOPYCNIC unless that shear is removed by baroclinic instability.

\subsection{Forcing}

The models are driven by forcing fields derived from global 6-hourly analyses performed at ECMWF. The seasonal atmospheric forcing is a monthly-mean climatology obtained for the years 1986 to 1988.

For the surface heat flux we have used the formulation by Barnier, Siefridt and Marchesiello (1995) which can be interpreted as a relaxation of the model surface temperature towards an equivalent surface temperature. Both the equivalent temperature and the spatially and seasonally varying restoring parameter are derived from the ECMWF analyses. In order to account for the presence of sea ice which is not otherwise included in the three models, the heat flux is set to zero whenever the surface temperature falls below $-1.8^{\circ} \mathrm{C}$. For the fresh water forcing a relaxation of the model surface salinity to the climatological values provided by Levitus (1982) has been used, with a time scale identical to that given by the formulation of the heat flux. The wind stress is also derived from the same ECMWF wind analyses (Siefridt, 1994), using the stress formulation proposed by Kondo (1975).

All forcing fields were converted to pseudo fields as proposed by Killworth (1996), in order to achieve the correct monthly means.

\subsection{Boundary conditions}

The model domain is connected to the Greenland/Norwegian Sea at $70^{\circ} \mathrm{N}$, and to the South Atlantic at $20^{\circ} \mathrm{S}$. The boundary conditions must therefore allow for important exchange processes across these boundaries. Furthermore, the influence of Mediterranean Water has also to be simulated.

This has been achieved by restoring temperatures and salinities to climatological values near 
the northern boundary and near Gibraltar for all three models. For the northern boundary, relaxation timescales increased from 3 days at $70^{\circ} \mathrm{N}$ to 100 days at the Greenland-Iceland-Scotland ridge. The timescale at the Strait of Gibraltar $\left(36^{\circ} \mathrm{N}, 6^{\circ} \mathrm{W}\right)$ was taken as 14 days, and was assumed to increase linearly to 100 days at a radius of $300 \mathrm{~km}$. Here, the relaxation zone extended out to $11^{\circ} \mathrm{W}$, and to $33.5^{\circ} \mathrm{N}$ and $38^{\circ} \mathrm{N}$, and only the upper $2500 \mathrm{~m}$ (or down to the interface of layers 14 and 15 for ISOPYCNIC) of the water column was relaxed in this way, in order to cover the expected depth range of the Mediterranean outflow water masses.

At the southern boundary, the conditions for the three models were not identical. For LEVEL an open boundary condition has been applied at $20^{\circ} \mathrm{S}$ following the algorithm developed by Redler and Böning (1997). Here temperature and salinity are prescribed only on inflow points, and in addition the normal component of the barotropic velocity is prescribed according to the Sverdrup relation. For ISOPYCNIC and SIGMA, a restoring condition has been applied in the region 19$11.5^{\circ} \mathrm{S}$, with the same restoring timescales as at the northern boundary. The rationale for this choice was to allow the three models to optimize their performance at the southern boundary. While the formulation has some influence on the circulation near and south of the equator, its influence on the North Atlantic circulation for an integration over 20 years is expected to be insignificant.

For the restoring data near the northern boundary, the Levitus data set is poorly suited because it exhibits strongly smoothed fields which do not agree with the observed structure of narrow boundary currents, e.g. the East Greenland Current. A new data set has been constructed, using an objective analysis procedure in which the Levitus data serves as first-guess information. The details can be found in D97. The restoration has been applied north of $67^{\circ} \mathrm{N}$, and northeast of a line from $\left(10^{\circ} \mathrm{W}, 67^{\circ} \mathrm{N}\right)$ to $60^{\circ} \mathrm{N}$ at the models' eastern boundaries.

\subsection{Initialization and integration of main experiment}

The three models have been initialised with a state of rest using the Levitus climatology for the month of September, when the ocean is well stratified, and integrated over a period of 20 years. The last 5 years of these runs serve as the main analysis period for the model intercomparison.

The choice of a 15-year spin-up period is motivated by the experience from previous model studies of the North Atlantic which showed that the velocity field reaches a dynamical quasiequilibrium state 10-15 years after a change of the external forcing. That time scale is governed by the passage of the lowest mode baroclinic Rossby wave across the basin, with regard not only to the wind forcing at the surface (Anderson, Bryan, Gill \& Pacanowski, 1979), but also to the thermohaline forcing at the surface and at the northern and southern boundaries which is responsible for the spin-up of the meridional overturning cell (Döscher et al., 1994; Gerdes \& Köberle, 1995).

The integration time of 20 years is very short compared to the thermohaline response time of the deep ocean. Hence, while the circulation is well-adjusted to the density distribution, it is far from the equilibrium response to the atmospheric conditions. In particular, the water mass distributions are far from equilibrium and reflect the initial state to a rather high degree. For this reason meaningful intercomparisons between the three models have to be restricted to dynamical parameters of the circulation. 


\subsection{Sensitivity experiments}

The basic DYNAMO experiment with SIGMA was the first of its kind, and no references existed for the degree of smoothing of the bottom topography. After the model integration had been completed, it appeared that the topographic smoothing has been excessive, resulting in rather wide shelf breaks at several key locations such as the Bahamas Bank, the Flemish Cap and the Iceland-Scotland Ridge. A sensitivity experiment (referred to as SIGMA-2) has then been carried out with a similar model configuration and forcing conditions, but a less smoothed bottom topography.

In SIGMA-2 the topographic smoothing consisted of passing a Lanczos filter on the $5^{\prime}$ topography, and then applying the median filter to interpolate onto the model grid. Subsequently, a series of weighted Shapiro filters has been passed to smooth the topography according to the criterion for pressure gradient calculation. The preliminary use of the Lanczos filter has resulted in only 10 passes of the Shapiro filters being necessary to satisfy the accuracy criterion and to reach convergence in the barotropic solver, whereas in the basic SIGMA experiment 100 passes of the selective Shapiro filter were necessary. Thus SIGMA-2 topography is much steeper and hence more realistic than that in SIGMA. The minimum depth is still kept to $200 \mathrm{~m}$ where the 20 sigma levels converge. Despite the steeper topography, the smoothing criterion is verified almost everywhere, except in very few localised areas of limited geographical extent.

The SIGMA-2 experiment includes 6 additional islands to compensate for the topographic smoothing. An island has been placed at Flemish Cap where the true ocean depth is less than $200 \mathrm{~m}$; two Bahamas Islands have been added to represent the Bahamas bank better; and three islands have been added to represent the Antilles with the underlying idea of investigating the effect of the islands on the passage of the North Brazil eddies into the Caribbean Sea (Barnier et al., 2001). The integration followed the same pattern as for the main experiment.

Further sensitivity experiments were carried out with LEVEL: a model run with daily wind stress fields based on ECMWF analyses; a run without wind forcing; and an experiment (referred to as LEVEL-KT) that included the mechanical part of a Kraus-Turner bulk parameterisation scheme. Its integration extended over 5 years and was initialised with the spin-up of LEVEL after 15 years.

\section{Results}

In the following, results of the main intercomparison experiments with regard to the mean general circulation are described. The results of various sensitivity experiments are included only insofar as they help to clarify specific aspects of the simulations.

\subsection{Meridional overturning circulation}

The North Atlantic is the region where most of the world ocean's deep water is formed. The ability of the three models to reproduce essential features of the thermohaline circulation is therefore an important aspect in evaluating their performance.

The overall structure of the thermohaline circulation is commonly described by the mean mer- 
idional overturning transport, defined as the annually averaged zonally integrated transport above a certain geopotential level. The corresponding stream function is given as

$$
\Psi(\varphi, z)=\int \mathrm{d} \lambda a \cos \varphi \int_{z}^{0} \mathrm{~d} z^{\prime} v\left(\lambda, \varphi, z^{\prime}\right)
$$

where $v$ is the meridional velocity. Fig. 2 shows that the overall strength of the thermohaline cell is fairly similar in all three models, with a maximum transport of 16-20 Sv. The spatial structure of the thermohaline cells is however distinctly different, indicating different pathways for deep water masses, in particular for the North Atlantic Deep Water (NADW).

In LEVEL the overflow of NADW across the northern ridges (Fig. 2a) amounts to $4 \mathrm{~Sv}$, and
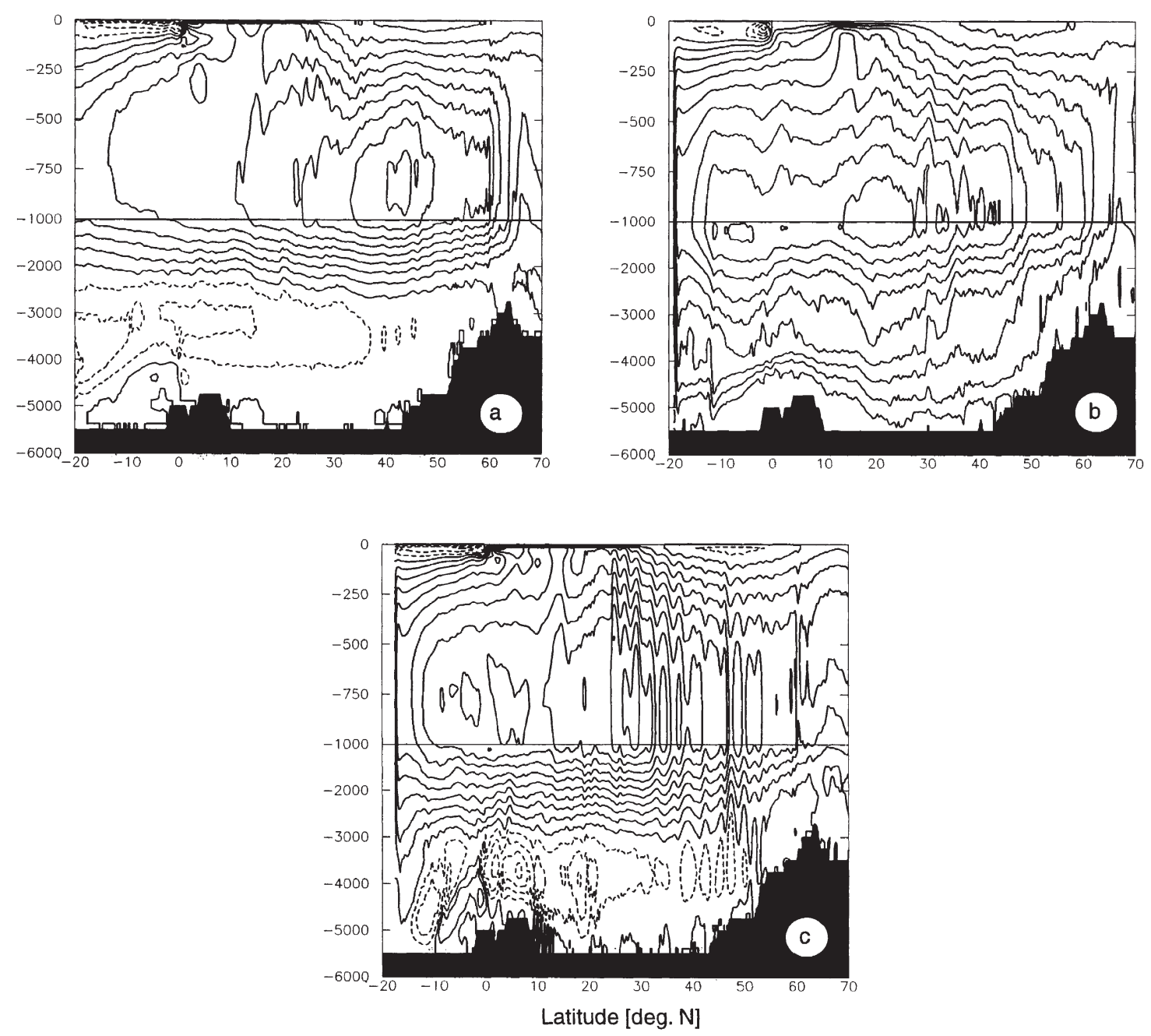

Fig. 2. Meridional overturning stream function vs. depth in different model simulations: a) LEVEL, b) ISOPYCNIC, c) SIGMA. Contour interval $2 \mathrm{~Sv}$. 
a further $8 \mathrm{~Sv}$ transport occurs north of $60^{\circ} \mathrm{N}$ through entrainment and/or sinking in the subpolar gyre. The NADW transport amounts to $12 \mathrm{~Sv}$ at the latitude of Cape Farewell, and further south the thermohaline cell increases to a maximum of $16 \mathrm{~Sv}$ at $40^{\circ} \mathrm{N}$ and $900 \mathrm{~m}$ depth. In ISOPYCNIC the overflow transport (Fig. 2b) is also $4 \mathrm{~Sv}$, but the total transport at $60^{\circ} \mathrm{N}$ is only $8 \mathrm{~Sv}$. Further sinking occurs fairly evenly between $60^{\circ} \mathrm{N}$ and $40^{\circ} \mathrm{N}$ originating from the Labrador and Irminger Seas, leading to a maximum overturning of $18 \mathrm{~Sv}$ at $20^{\circ} \mathrm{N}$ and $1000 \mathrm{~m}$. SIGMA (Fig. 2c) has the strongest overflow $(6 \mathrm{~Sv})$ which, however, is partly recirculated northwards. The sinking between $65^{\circ} \mathrm{N}$ and $55^{\circ} \mathrm{N}$ is weak, and at $60^{\circ} \mathrm{N}$ the total transport is still only $6 \mathrm{~Sv}$. Additional sinking is concentrated in several latitudinal bands down to $30^{\circ} \mathrm{N}$; the cell maximum is $20 \mathrm{~Sv}$ at $28^{\circ} \mathrm{N}$ and $800 \mathrm{~m}$. It is noteworthy that all models have succeeded in simulating an overflow with approximately the observed magnitude (cf. Dickson \& Brown, 1994), without substantial modifications, i.e. no artificial deepening of the bottom topography.

Both LEVEL and SIGMA have deep reverse cells but they are somewhat different in strength and pattern, whereas ISOPYCNIC has no reverse cell. LEVEL shows a northward flow below 3,500 m reaching $4 \mathrm{~Sv}$ which may be interpreted as transport of Antarctic Bottom Water (AABW). The reverse cell in SIGMA occurs at greater depth and is significantly stronger but also shows a number of closed recirculations, that makes the interpretation more difficult. The closed recirculations in SIGMA below $3500 \mathrm{~m}$ near the equator appear to be spurious. Almost identical recirculations were found in a coarse resolution $\left(1.2^{\circ}\right)$ version of SIGMA run with 20 levels, but vanished when this model was run with 35 vertical sigma levels (Knochel, 1998).

Overall the differences between LEVEL and ISOPYCNIC are qualitatively similar, but substantially lower in magnitude, than the corresponding differences in the intercomparison of 1-degree models by Chassignet, Smith, Bleck and Bryan (1996). In the tropical South Atlantic, AABW transports of 3-5 Sv have been estimated (Speer \& Zenk, 1993). McCartney and Curry (1993) estimated the cross-equatorial flow of AABW to be of the order of $4.3 \mathrm{~Sv}$. This value is in very good agreement with those from the LEVEL and SIGMA models (Fig. 2a and Fig. 2c), despite significantly different boundary conditions of both models at the southern limit of the model domain.

In the sensitivity experiment SIGMA-2 which has less smooth topography, the meridional overturning (not shown) is significantly weaker and reaches a maximum of only $12 \mathrm{~Sv}$. The reason for this difference can be found in the overflow over the Iceland-Scotland Ridge (ISR). Fig. 3 displays the topography along and the normal flow across that ridge for the three intercomparison models and for SIGMA-2. The reduced topographic smoothing in SIGMA-2 (Fig. 3d) reduces the widening of the channel width compared to SIGMA (Fig. 3c). The structure of the throughflows in SIGMA-2 is somewhat more baroclinic, and the amount of dense water $\left(\sigma_{\theta}>27.78\right)$ flowing over the ridge is reduced by $50 \%$, so that at $60^{\circ} \mathrm{N}$ the deep overflows in this experiment are half as strong as in SIGMA. Our interpretation is that the reduced topographic smoothing in SIGMA-2 creates a narrower shelf break where the outgoing flow of surface water and the incoming flow of dense water can co-exist one on top of the other (i.e., the width of each current is equal to the width of the break). The vertical shear is increased so the flow is more baroclinic. In SIGMA, the width of the break is almost twice the width of the currents, and the deep flow is shifted to the east of the surface flow. This produces more intense and barotropic flows, because the inflow and outflow currents do not exchange momentum. However, this interpretation needs some caution, since it is unclear whether the changes in overflow result from these local changes in 

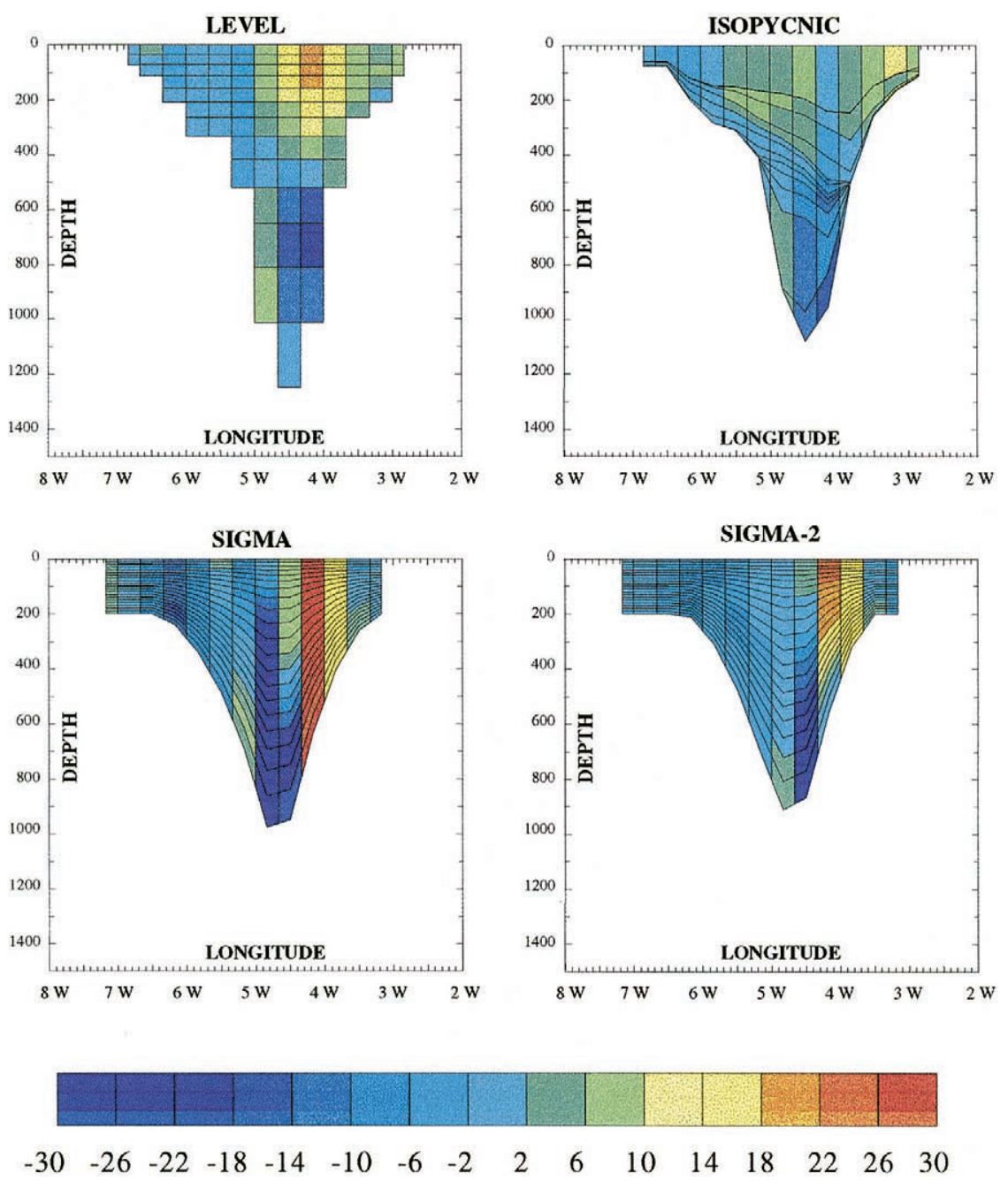

Fig. 3. Normal velocity (in $\mathrm{cm} / \mathrm{s}$ ) across the Iceland-Scotland Ridge, displayed in the native grids of the models. Negative values (blue colours) correspond to flow out of the Norwegian Sea. a) LEVEL, b) ISOPYCNIC, c) SIGMA, d) SIGMA-2.

topography alone, and are not being influenced by circulation changes at larger scales. In ISOPYCNIC the flow field is most baroclinic, and the overflow is weaker, whereas in LEVEL the outflow resembles that of SIGMA-2.

The vertical motion associated with the meridional transport as defined by Eq. (3) does not necessarily correspond to a diapycnal transport but can also describe isopycnal flows which sink at one latitude and rise at another. This is the case e.g. for the so-called Deacon cell in the Antarctic Circumpolar Current, as shown by Döös and Webb (1994). An alternative view of the thermohaline transport which focusses on diapycnal transports, can by obtained by considering the transport above a surface of constant density, ideally a neutral surface. In order to facilitate intercomparison of all three models, we have chosen instead surfaces of constant potential density 
$z=h\left(\lambda, \varphi, \sigma_{\theta}\right)$. While that choice is clearly problematic in low latitudes and in the South Atlantic where the presence of Antarctic Bottom Water causes unstable stratification of $\sigma_{\theta}$, in the midand high latitude North Atlantic it is likely to give a fair description of diapycnal transports, to the extent that the flow is steady (see the discussion by Hirst, Jackett \& McDougall, 1996). The zonally integrated transport vs. density is then described by the stream function

$$
\Psi_{*}\left(\varphi, \sigma_{\theta}\right)=\int \mathrm{d} \lambda a \cos \varphi \int_{h\left(\lambda, \varphi, \sigma_{\theta}\right)}^{0} \mathrm{~d} z^{\prime} v\left(\lambda, \varphi, z^{\prime}\right)
$$

which is displayed in Fig. 4 The plot is restricted to densities $\sigma_{\theta}>27.0$ so that primarily the circulation below the main thermocline can be seen. Note that strictly the interpretation as diapycnal transport is correct only for a time-independent flow, and any trend based on the 5
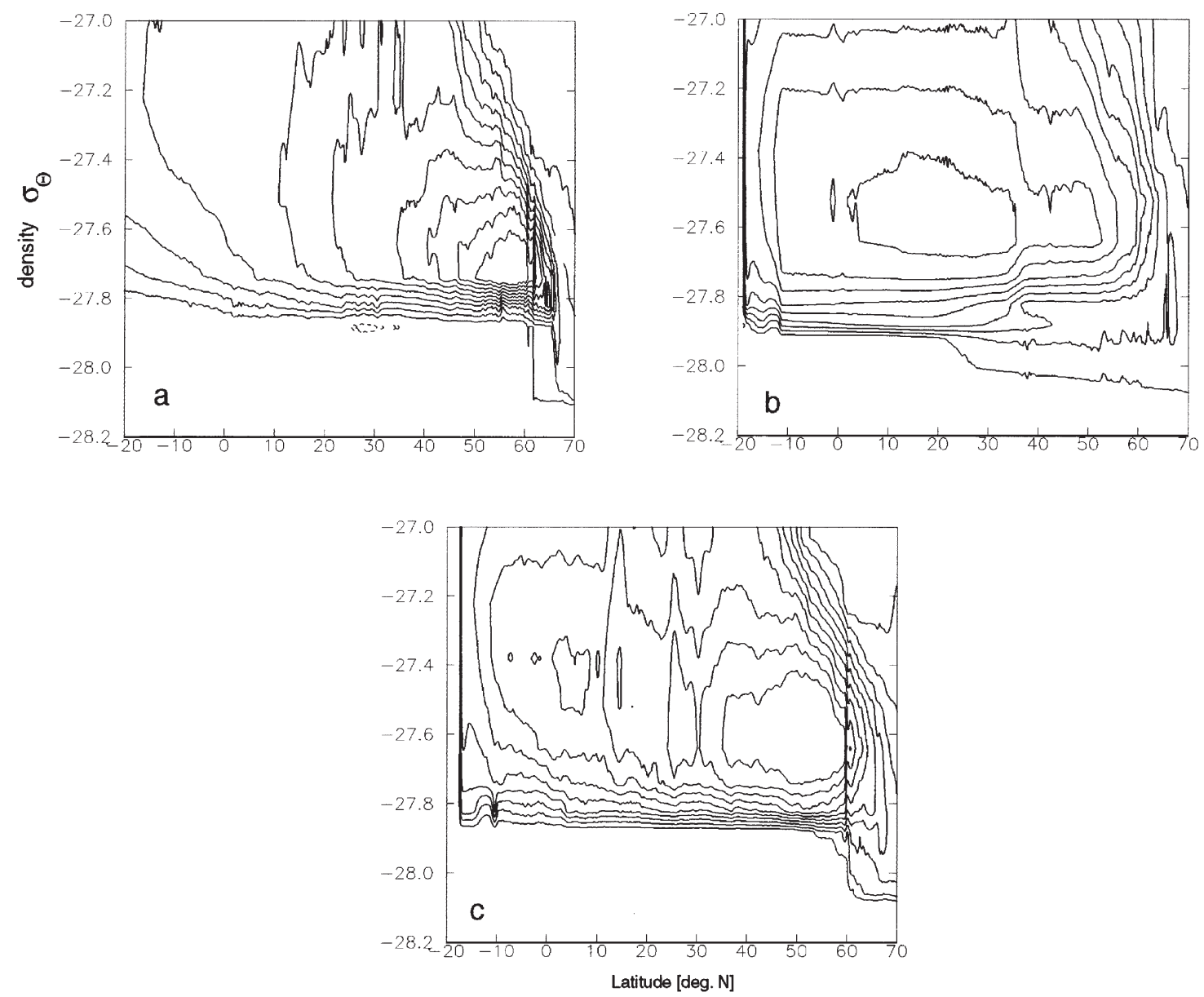

Fig. 4. Meridional overturning stream function vs. density $\sigma_{\theta}$ in different model simulations: a) LEVEL, b) ISOPYCNIC, c) SIGMA. Contour interval 2 Sv. 
years of averaging could in principle induce a spurious signal (cf. Marsh, Nurser, Megann \& New, 2000).

Note first that any 'overturning' circulation in this representation includes the influence of the horizontal gyres, if their northward and southward branches occur at different densities. This should be the case particularly in the subpolar North Atlantic, in which the flow of warm water by the North Atlantic Current system is gradually cooled along its northward paths in the Irminger and Iceland Basins, and then is returned south both at depth and by near-surface currents along the Greenland and Labrador shelves. All three models show this expected mismatch in the strengths of the different integral representations: near the center of the subpolar gyre at $55^{\circ} \mathrm{N}$, the 'overturning' transport in density space is larger by $\sim 6 \mathrm{~Sv}$ in LEVEL and ISOPYCNIC than the standard overturning, and by $10 \mathrm{~Sv}$ in SIGMA, reflecting a significant contribution of horizontal gyre circulations to the meridional buoyancy transport. Farther south, there is an interesting difference in this 'gyre' contribution between the models. In both LEVEL and ISOPYCNIC it diminishes to $<1 \mathrm{~Sv}$ south of about $45^{\circ} \mathrm{N}$, but it remains a significant factor in SIGMA at mid-latitudes: e.g., with about $6 \mathrm{~Sv}$ at $35^{\circ} \mathrm{N}$, the latitude of Cape Hatteras.

According to the host of sensitivity studies carried out under the CME (e.g, Döscher et al., 1994), the density of the outflow from the Nordic Seas should be an important factor governing the net deep water production and meridional overturning. As seen from Fig. 4, the water mass transformation at high latitudes is strikingly different between LEVEL and SIGMA on the one hand, and ISOPYCNIC on the other. North of $65^{\circ} \mathrm{N}$, all three models have similar deep densities around 28.1, as a result of the northern restoring zone. However, pronounced diapycnal transport is evident in both LEVEL (Fig. 4a) and SIGMA (Fig. 4c) between $66^{\circ} \mathrm{N}$ and $61^{\circ} \mathrm{N}$, i.e. in the latitude range immediately south of the Denmark Strait. Within a few hundred kilometers, both models have lost 0.2 units in density which corresponds to a warming of approximately $2^{\circ} \mathrm{C}$. Nothing comparable occurs in ISOPYCNIC (Fig. 4b) where the density of the outflow decreases uniformly, and remains $>28.0$ even at $30^{\circ} \mathrm{N}$. This behaviour indicates that there are substantial differences between the three models in the effective diapycnal mixing in the region where the overflows crossing the Denmark Strait and across the Iceland-Scotland Ridge sink to greater depths and increase their transport by entraining surrounding water (see D97 for a more detailed discussion).

In LEVEL and SIGMA, diapycnal mixing can occur in three ways, namely:

i) explicitly through vertical diffusion according to (1) which occurs predominantly in regions of weak stratification, and which includes convective adjustment in case of static instability;

ii) through the biharmonic horizontal diffusion in regions of strong isopycnal slopes; and

iii) through truncation in the numerical advection operators.

For LEVEL, it has often been demonstrated that the step-wise representation of topography induces strong unphysical diapycnal mixing in density-driven flows down a sloping bottom, as a result of the interaction of horizontal diffusion with convection (e.g., Roberts et al., 1996; Beckmann \& Döscher, 1997). For SIGMA, the reason for the strong localised mixing is less clear, since that model is designed to represent such downslope flows well. It appears that (realistic) strong horizontal density gradients in the overflow region, in combination with biharmonic 
diffusion along horizontal rather than isopycnal surfaces, are responsible for too much overall diapycnal mixing.

In an isopycnal model, diapycnal mixing can only occur explicitly through the parameterization Eq. (1), and there is no unphysical mixing affecting the density. The present model formulation, however, does not account sufficiently for the strong mixing resulting from entrainment of ambient water into the outflow regime (Baringer \& Price, 1997). Hence in ISOPYCNIC the deep densities are not only higher than those of the other two models, but also significantly exceed the deep climatological values throughout the mid-latitudes. For example, the deep temperatures in the eastern basin at $48^{\circ} \mathrm{N}$ (not shown) are $3^{\circ} \mathrm{C}$ colder than the Levitus climatology. As the model was initialized with the Levitus climatology, this must be the result of advection of cold overflow water (mainly from the Iceland-Scotland Ridge) within the twenty years of integration. It appears that in ISOPYCNIC the overflows largely preserve their water mass characteristics, and that there is less mixing than actually occurs in nature. In other words, the parametrization Eq. (1) which has been used by all models is clearly inadequate in the overflow region.

The southward flow of upper NADW also evolves in a strikingly different way in ISOPYCNIC (Fig. 4b) than in the other models. While in both LEVEL and SIGMA there is a gradual erosion of the southward transport of upper NADW by diapycnic mixing (most strongly in LEVEL), both the density and the net southward transport increase in ISOPYCNIC although the density of the lower NADW decreases. The mixing is concentrated around $35^{\circ} \mathrm{N}$ where the density of the upper southward branch increases by nearly 0.1. This behaviour is not a generic property of ISOPYCNIC, but related to the specific implementation of the restoring condition in the Mediterranean outflow regime which causes the conversion of NADW to a denser water mass; for a detailed discussion see Jia (2000) and Killworth (1999).

As seen from Fig. 4a, strong diapycnal upwelling occurs in LEVEL between $50^{\circ} \mathrm{N}$ and $20^{\circ} \mathrm{N}$. Correspondingly, the thermohaline transport is much weaker at low latitudes than in both the other models. The upwelling appears to be rather localised inside the region of the western boundary current, and is caused by the biharmonic horizontal diffusion. In coarse-resolution level-models such spurious upwelling is regularly present, and can be eliminated by replacing horizontal diffusion with the Gent-McWilliams eddy-transport scheme (Böning, Holland, Bryan, Danabasoglu \& McWilliams, 1995). It appears that even at eddy-permitting resolution a non-diffusive form of the unavoidable dissipation is preferable to suppress the unphysical upwelling. The same phenomenon is also present in SIGMA, but to a much lesser extent.

Previous sensitivity studies based on the CME configuration (Böning, Bryan, Holland \& Döscher, 1996) found the deep winter convection in the subpolar North Atlantic of secondary importance for the overall meridional overturning, compared to the effect of the outflows. The behaviour of the present sensitivity experiments is in accordance with this result. Fig. 5 shows the mean mixed-layer depth in winter for the three basic model versions, and also for the sensitivity cases SIGMA-2 and LEVEL-KT. (The focus here is on the deep convection in the subpolar gyre; for a discussion of the mid-latitude distribution we refer to New, Jia, Coulibaly and Dengg (2001).). All models exhibit the characteristic increase in ML depth along the cyclonic path of the North Atlantic waters. In the northeastern basin values exceed $500 \mathrm{~m}$, in fair agreement with McCartney and Talley (1982). The region where the models differ most strongly is the Labrador Sea. SIGMA (Fig. 5c) results in a shallow mixed layer, which nearly everywhere is less than $600 \mathrm{~m}$ deep, with no sign of any deep convection. On the other hand, in LEVEL (Fig. 5a) the 

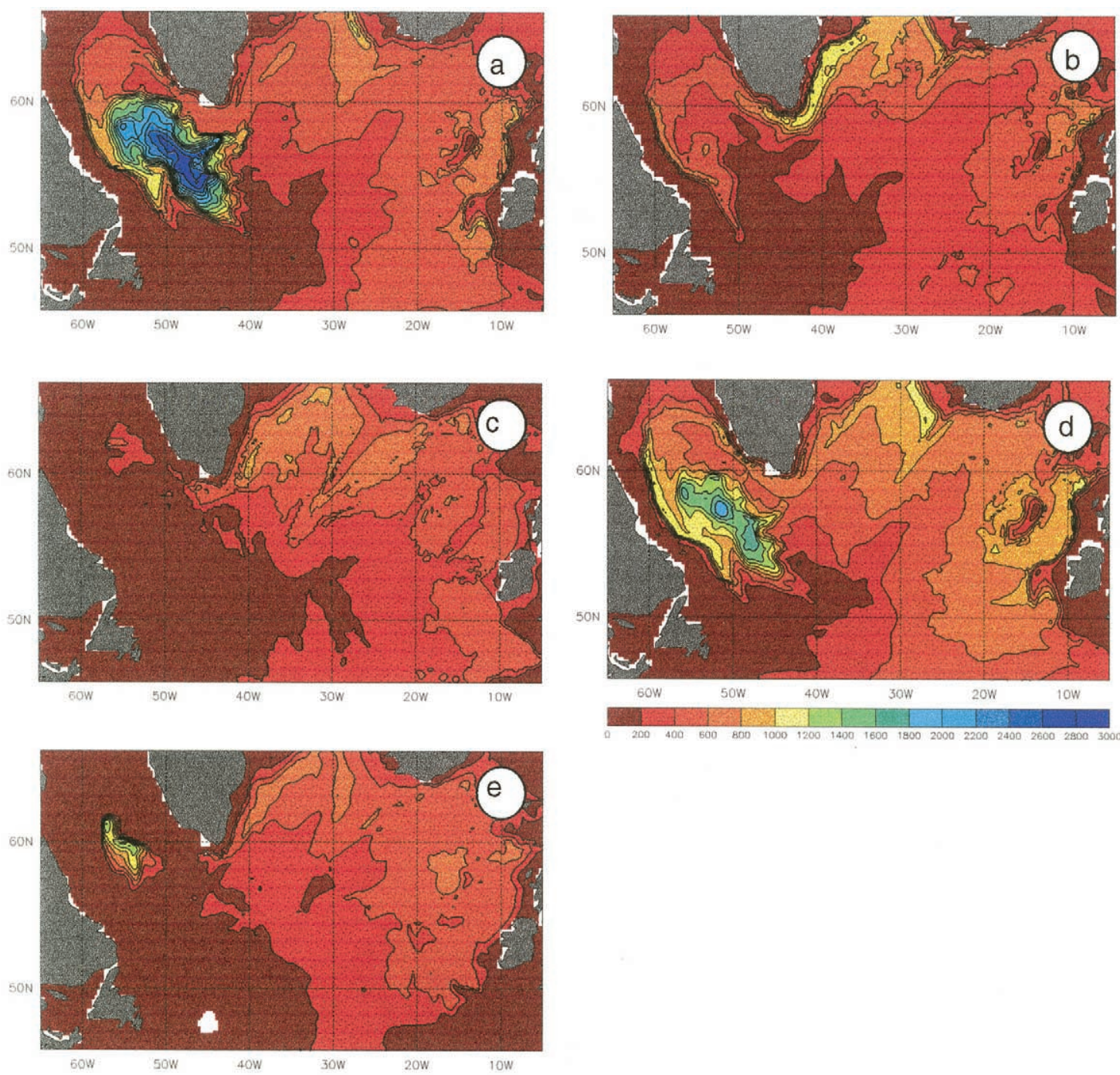

Fig. 5. Depth of mixed-layer in winter in different model simulations: a) LEVEL, b) ISOPYCNIC, c) SIGMA, d) LEVEL-KT, e) SIGMA-2. Contour interval $200 \mathrm{~m}$.

ML depth is $>1000 \mathrm{~m}$ over much of the cyclonic gyre in the Labrador Sea, reaching almost to the bottom in the center. ISOPYCNIC (Fig. 5b) is between these extremes, with ML depths between 200 and $600 \mathrm{~m}$ over most of the region, exceeding $1000 \mathrm{~m}$ only in the boundary current and a small area near $57^{\circ} \mathrm{N}$.

While the convection depth of the three models is strikingly different, it is likely that these differences are not immediately related to the different numerical concepts. The sensitivity studies show that other factors also contribute, and it is possible to get equally strong differences between realizations of the same model. LEVEL-KT (Fig. 5d) shows maximum convection to $2000 \mathrm{~m}$ in the Labrador Sea, but increased depths in the Irminger Basin, and appears generally more similar 
to the mixed layer structure of ISOPYCNIC. The unusual behaviour of SIGMA is obviously related to the near-surface circulation which advects warm waters from the south into the Labrador Sea (cf. the discussion of Fig. 12 below). The modified flow field in SIGMA-2 (Fig. 5d), with a lower transport of warm water into the Labrador Sea, allows much stronger and deeper convection in the Labrador Sea than in SIGMA. It is interesting to note that the meridional overturning in SIGMA-2 is much reduced compared to SIGMA, lending support to the hypothesis that the convection in the Labrador Sea is of secondary importance for the overall meridional overturning.

\subsection{Thermohaline transport in the subtropical gyre}

The actual overturning transport cannot be observed directly, and indirect estimates differ substantially, especially concerning the latitudinal distribution, depending on which method and which observations are used for its determination. The most favorable latitude for a quantitative test of model solutions is at $25^{\circ} \mathrm{N}$, where a combination of good quantitative knowledge of the western boundary currents, repeatedly measured transoceanic sections, and low values of both eddy variability and long-term changes has contributed to remarkably stable estimates of the net meridional transport of 17-18 Sv (Hall \& Bryden, 1982; Roemmich \& Wunsch, 1985; Macdonald, 1998; Lavin, Bryden \& Parilla, 1998).

A model-data comparison at this latitude, in particular, allows a detailed view of the vertical structure of the thermohaline transport. In Fig. 6 the zonally integrated transport per unit depth is displayed, including the transport estimates based on inverse calculations from hydrographic section data taken in 1981 (Roemmich \& Wunsch, 1985). The observed transport shows a clear

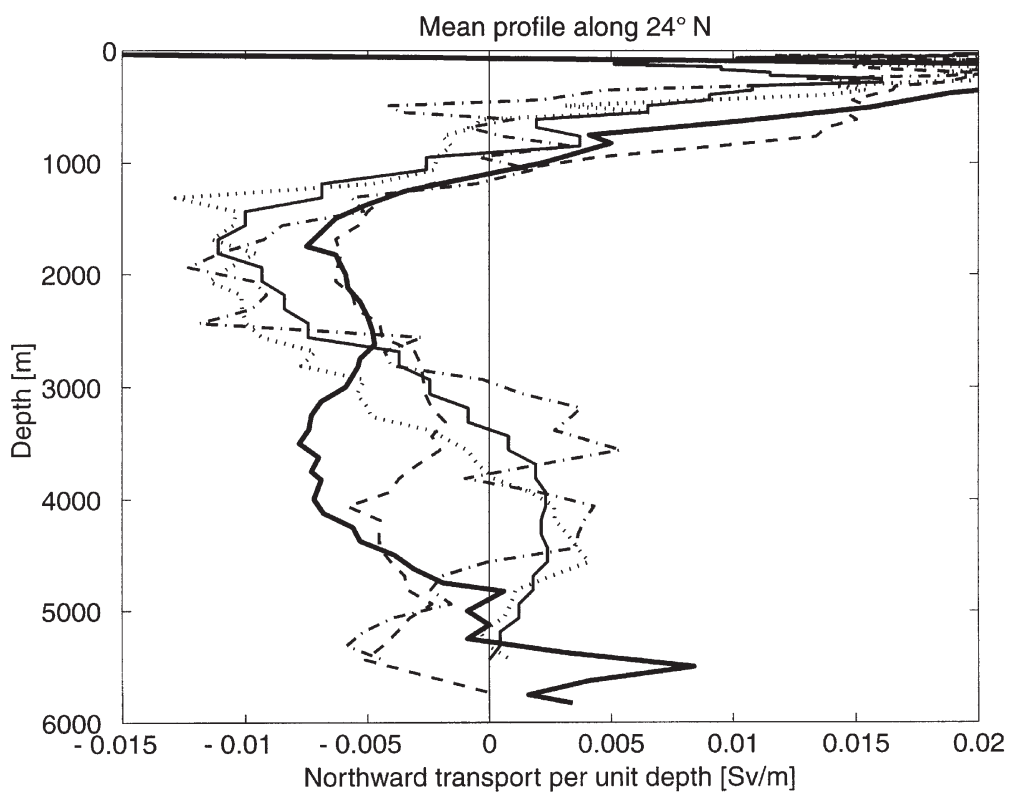

Fig. 6. Overturning transport per unit depth at $24^{\circ} \mathrm{N}$ vs. depth for different models. Full thin line LEVEL, dashed ISOPYCNIC, dotted SIGMA, dash-dotted SIGMA-2. The heavy full line shows the estimate by Roemmich and Wunsch (1985) based on a $24^{\circ} \mathrm{N}$ section taken in 1981. 
separation between upper (maximum at $1600 \mathrm{~m}$ ) and lower (maximum at 3-4 km) branches of NADW. The lower branch of the NADW is also present in the analysis by Rintoul and Wunsch (1991). A more recent analysis (Macdonald, 1998) also suggests that the zonally integrated transport between $1500 \mathrm{~m}$ and $5000 \mathrm{~m}$ is southwards, with a secondary maximum below $4000 \mathrm{~m}$. Note however that the vertical structure of the southward transport exhibits some natural variability: both the 1957 IGY data and the WOCE section of 1992 indicated considerably weaker transport of lower NADW, and a more pronounced expression of the upper branch (Lavin et al., 1998).

The simulated northward flow of main thermocline water occurs above $1000 \mathrm{~m}$ in ISOPYCNIC, but is more concentrated above $500 \mathrm{~m}$ in LEVEL and SIGMA. The spreading of NADW occurs between 1000 and $3500 \mathrm{~m}$ in both LEVEL and SIGMA, with only one maximum near $2000 \mathrm{~m}$. Below $3500 \mathrm{~m}$, both models show northward transport (more pronounced in SIGMA) associated with AABW. Both SIGMA and LEVEL fail to reproduce the lower branch of the NADW. The structure of the southward flow in ISOPYCNIC is different, with two maxima at 2000 and at $4000 \mathrm{~m}$, respectively, corresponding to the upper and lower branches of NADW. Hence of the three models, ISOPYCNIC is the only one in which there is identifiable lower NADW transport between 3500 and $5000 \mathrm{~m}$. However, ISOPYCNIC has no northward transport at all in the deep ocean, and thus fails to reproduce the northward AABW transport.

The absence of lower NADW-transport in LEVEL and SIGMA is not an inherent defect of these models but reflects the lack of sufficiently dense waters in the northern Irminger and Iceland Basins that has been discussed above. This is demonstrated by the results of Döscher et al. (1994) who using a level model obtained a pronounced transport maximum below $4000 \mathrm{~m}$ depth when assuring the presence of sufficiently dense deep water north of $60^{\circ} \mathrm{N}$. In their study, this was achieved through the formulation of a restoring boundary condition southward of the sills which resembled the deep water formation through overflows that were not explicitly included. The reason for the absence of sufficiently dense water has already been discussed, namely the strong and localised mixing downstream of the Greenland-Iceland-Scotland overflow. Note that the transport for SIGMA-2 which is also shown in Fig. 6 confirms this conclusion, it has less deep water flowing over the sills and correspondingly has a southward transport at shallower depth (the transport below $4500 \mathrm{~m}$ is associated with a rather localised cell). We must therefore conclude that the same mechanism which leads to locally enhanced mixing is also responsible for important aspects of the large-scale structure of the thermohaline circulation.

The absence of AABW transport in ISOPYCNIC points to a generic problem in this model which uses $\sigma_{\theta}$ to define its vertical coordinate. As a result of its construction, this model is deficient both in its equation of state, by not allowing for the compressibility of seawater, and in its representation of the thermal wind relation. Therefore, unlike the other two models, it cannot strictly converge towards the correct continuous form of the primitive equations of motion, even when the number of layers is very large. One well-known consequence of this deficiency is that the water mass distributions associated with the AABW cannot be properly represented, since this would give rise to an inversion in the $\sigma_{\theta}$ coordinate which cannot be supported by the model. Furthermore, the velocity shear at large depths in ISOPYCNIC can differ substantially from its correct value which is connected to gradients of the in-situ density rather than of $\sigma_{\theta}$. These problems cannot be resolved through the choice of a different reference pressure for the potential density. They can, however, be largely reduced by choosing a density variable that is more representative of the local potential density (Eden \& Willebrand, 1999) or by changing the 
equation of state to include thermobaric effects (Sun, Bleck, Rooth, Dukowicz, Chassignet \& Killworth, 1999).

To a large extent, the thermohaline transport occurs through narrow Western Boundary Currents. A section of the meridional velocity near the western boundary at $27^{\circ} \mathrm{N}$ is shown in Fig. 7. The structure of the boundary current system in all three models is fairly similar, with the exception that the smoother topography in SIGMA leads to a connection between Antilles Current and Florida Current which are topographically separated in the other two models, and also in SIGMA-2 (not shown). The observations by Lee, Johns, Zantopp and Fillenbaum (1996) (their Fig. 3c) show that there is a Deep Western Boundary Current (DWBC) within less than $50 \mathrm{~km}$ of the continental shelf, that reaches maximum velocities of $15 \mathrm{~cm} / \mathrm{s}$ below $2000 \mathrm{~m}$ depth. Obviously, such a structure can barely be resolved with the model's grid size which at this latitude is $33 \mathrm{~km}$. Nevertheless, all three models show a clear DWBC core within $100 \mathrm{~km}$ of the boundary,
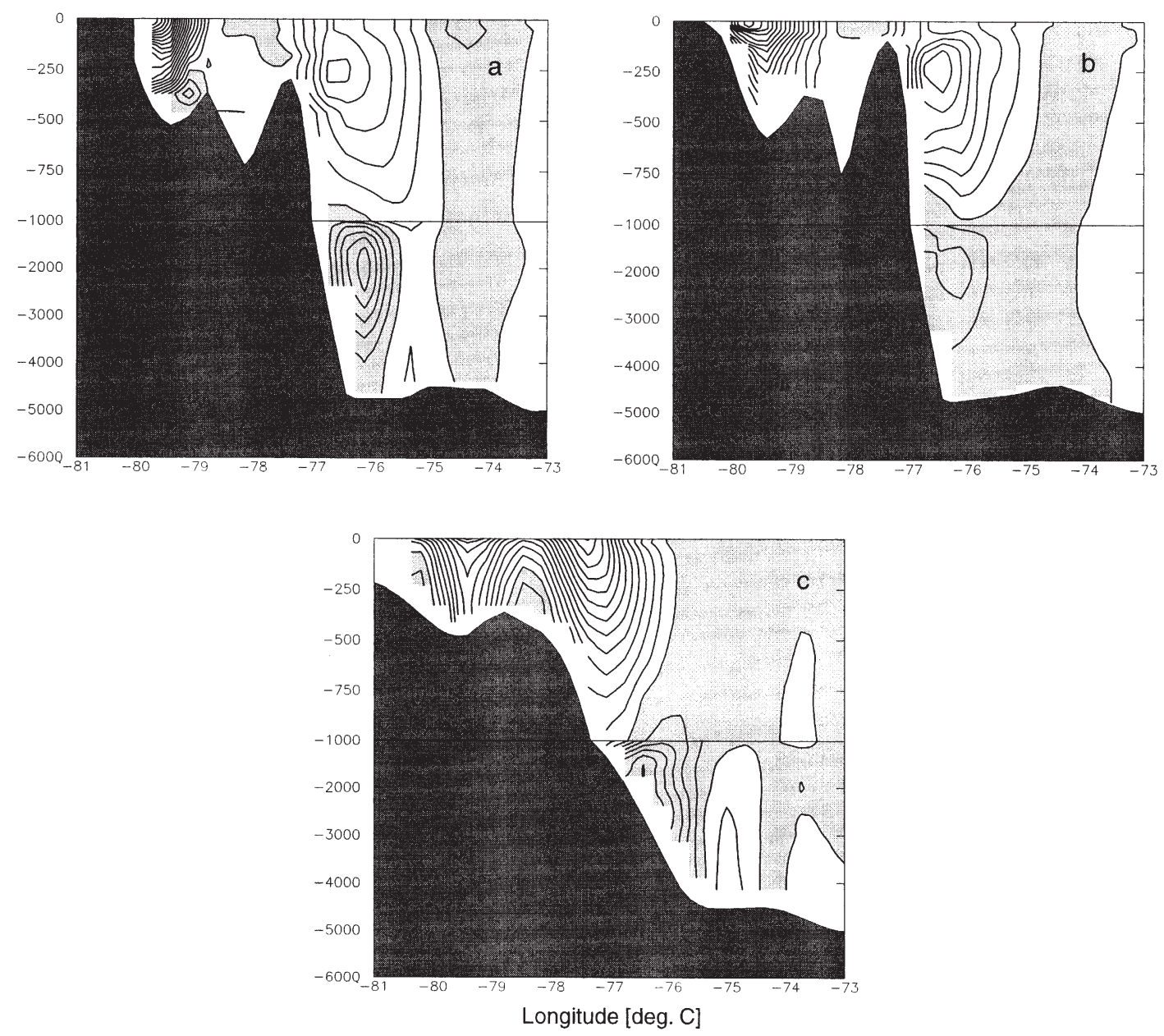

Fig. 7. Meridional velocity across $7^{\circ} \mathrm{N}$ for different models: a) LEVEL, b) ISOPYCNIC, c) SIGMA, and d) SIGMA2. Contour intervals $5(2.5) \mathrm{cm} / \mathrm{s}$ above (below) $1000 \mathrm{~m}$. Shaded regions correspond to southward velocities. 
which is strongest $(15 \mathrm{~cm} / \mathrm{s})$ and most attached to the continental slope in SIGMA, and weakest $(7 \mathrm{~cm} / \mathrm{s})$ and most detached from the slope in ISOPYCNIC.

The partition of the thermohaline transport in the three models between the Western Boundary Current and the interior is summarised in Fig. 8. Despite the differences in the spatial structure, the northward boundary current transport (35-38 Sv) is nearly identical in all three models. The Deep Western Boundary Current transport in LEVEL and SIGMA is also rather similar, 17 and $16 \mathrm{~Sv}$, respectively. It is interesting to note that in LEVEL the overturning is generally larger than in the previous CME runs, even compared to those CME experiments which used a relaxation to an observed hydrographic section to represent the effect of overflow. In the interior both LEVEL and SIGMA have a weak northward transport (4 and $2 \mathrm{~Sv}$, respectively) which is accompanied by substantial recirculation patterns. These values agree well with the estimates by Schmitz and McCartney (1993) who find $17 \mathrm{~Sv}$ for the DWBC transport between 1.8 and $4^{\circ} \mathrm{C}$. The sensitivity experiment with LEVEL without wind forcing resulted in a DWBC transport of
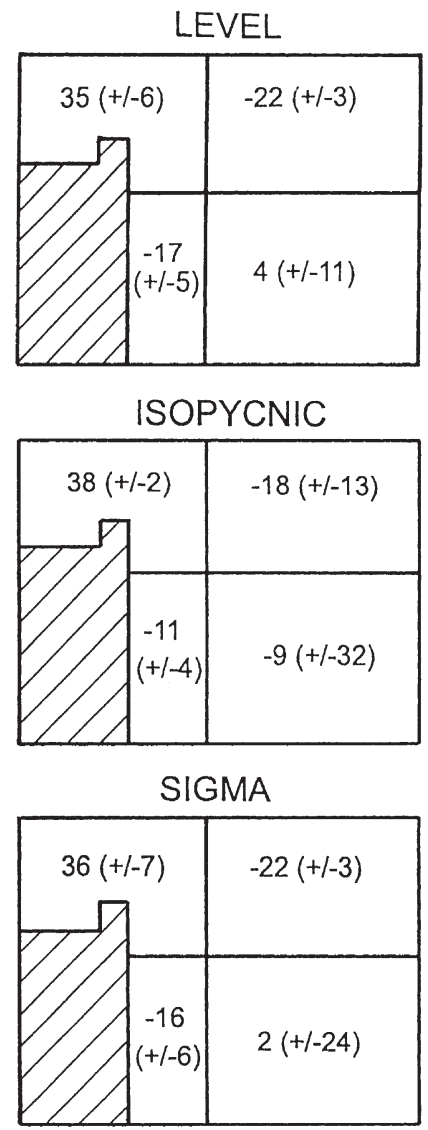

Fig. 8. Partition of transport values (in Sv) above and below $1000 \mathrm{~m}$ at $25^{\circ} \mathrm{N}$, between western boundary and $73^{\circ} \mathrm{W}$ and $73^{\circ} \mathrm{W}$ and eastern boundary, respectively, for the three intercomparison models. The first value gives the net transport, the second the amount of recirculation through the respective section. 
$20 \mathrm{~Sv}$, that was nearly compensated by an upper layer WBC transport of $17 \mathrm{~Sv}$, confirming that the wind forcing is not important as a driving force of the DWBC.

The DWBC transport in ISOPYCNIC is significantly lower at $11 \mathrm{~Sv}$, with an interior transport that is again southwards (9 Sv), accompanied by $32 \mathrm{~Sv}$ of recirculation which occurs mainly in the eastern basin below $4000 \mathrm{~m}$. In ISOPYCNIC (and to some degree also in SIGMA), water resulting from the overflow through the Faroe-Scotland Channel appears to be transported in a boundary current along the eastern flank of the Mid-Atlantic Ridge (MAR), probably because the core is too deep (i.e., too dense) to cross through the Gibbs Fracture Zone into the western basin. The partition between WBC and interior depends of course on the exact location of the box boundary which, at this latitude, has been defined somewhat arbitrarily as $73^{\circ} \mathrm{W}$; with a partition at $71^{\circ} \mathrm{W}$ rather than $73^{\circ} \mathrm{W}$ the WBC transport in ISOPYCNIC would increase to $14 \mathrm{~Sv}$, the interior transport decreases to $6 \mathrm{~Sv}$. The total deep transport of $20 \mathrm{~Sv}$ at $25^{\circ} \mathrm{N}$ in ISOPYCNIC is however substantially above both other models (13 and $14 \mathrm{~Sv}$ respectively).

\subsection{Heat transport and ocean-atmosphere fluxes}

The meridional heat transport is a variable of great climatological interest. It is closely related to the surface heat flux, but differences in heat storage of the models which are not in full thermal equilibrium may complicate the interpretation of this variable which should therefore be considered with some caution.

There are some distinct differences in meridional heat transport between the three models that are apparent in Fig. 9. In ISOPYCNIC and SIGMA the maximum reaches almost 1.2 PW, and occurs at $20^{\circ} \mathrm{N}$ in ISOPYCNIC and between $20-35^{\circ} \mathrm{N}$ in SIGMA. North of $35^{\circ} \mathrm{N}$ the SIGMA heat transport is significantly (up to $0.2 \mathrm{PW}$ ) larger. North of $20^{\circ} \mathrm{N}$ both models are within the

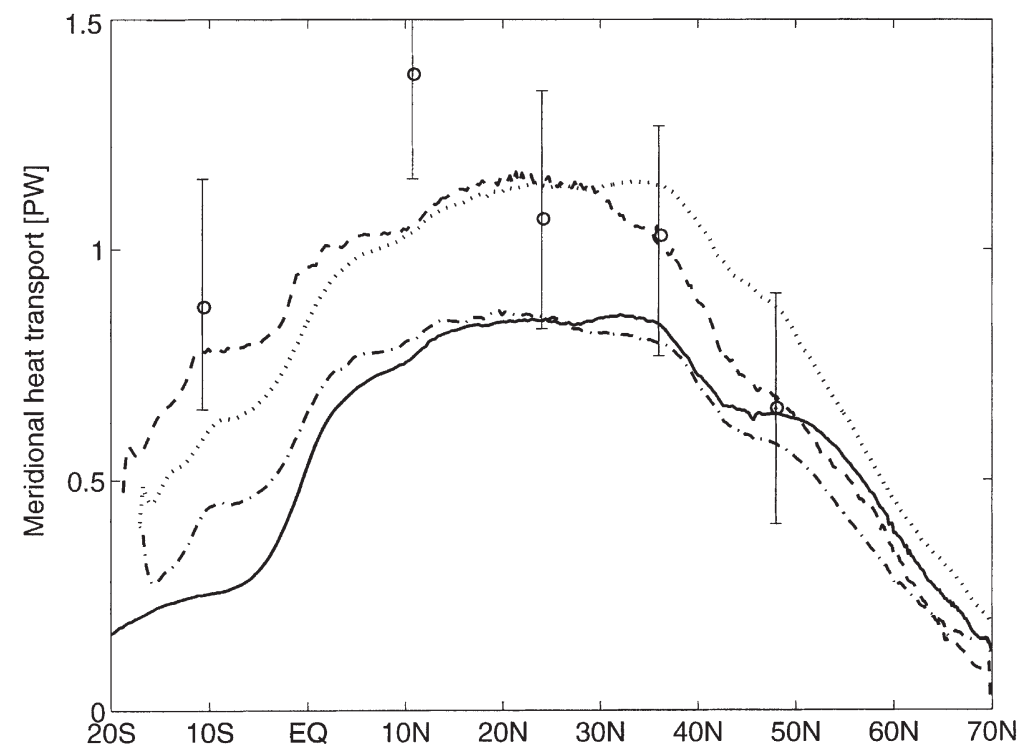

Fig. 9. Northward transport of heat in different model simulations. Full line is LEVEL model, dashed ISOPYCNIC, dotted SIGMA, dash-dotted SIGMA-2. Values with error bars are estimates from Macdonald and Wunsch (1996). 
error bars of the recent estimates from hydrographic sections (Macdonald, 1998), but south of $20^{\circ} \mathrm{N}$ the models are somewhat lower; In LEVEL the heat transport is substantially lower (up to $0.4 \mathrm{PW}$ ) than in the other models and is less than observations, except in the subpolar region; it reaches a maximum of only $0.85 \mathrm{PW}$ between $20-35^{\circ} \mathrm{N}$. Remarkably, the meridional heat transport in the sensitivity experiment SIGMA-2 (carried out with the SPEM code with less topographic smoothing) is very similar to LEVEL with a maximum heat transport of $0.86 \mathrm{PW}$ at $25^{\circ} \mathrm{N}$.

A qualitatively similar difference between a geopotential level and an isopycnal model has been found in the intercomparison by Chassignet et al. (1996). The cause for the much lower heat transport in LEVEL and SIGMA-2 is related to weaker meridional overturning transport in these experiments. The relation between heat transport and overturning rate at $25^{\circ} \mathrm{N}$ for all models (Fig. 10) coincides rather well with the almost linear relation found in a number of integrations by Böning et al. (1996) and also in recent integrations with very high resolution (R. Smith \& E. Chassignet, 1998, pers. comm.), demonstrating that the heat transport is dominated by the overturning component.

It is noteworthy that all three models are very similar at $60^{\circ} \mathrm{N}$, predicting a value of $0.4 \mathrm{PW}$, which is on the high side of most published estimates. Only SIGMA-2 has a lower value (0.3 PW), an immediate consequence of its lower overturning.

The zonally averaged surface heat flux (Fig. 11) is fairly similar in all three models. In all three models, the region of oceanic uptake of heat is fairly concentrated around the equator, with the highest values in LEVEL. The ECMWF analysis has a lower maximum but a larger scale, a consequence of the much coarser resolution of the atmospheric analysis. The heat uptake in ISOPYCNIC is most concentrated, and between $3^{\circ} \mathrm{N}$ and $10^{\circ} \mathrm{N}$ that model deviates significantly from the other two with nearly vanishing heat exchange.

Over much of the subtropical gyre between $10^{\circ} \mathrm{N}$ and $30^{\circ} \mathrm{N}$, all models have a nearly vanishing net flux, which is within the error bars of the recent climatological estimate by Hasse, Lindau and Ruprecht (1996). The heat flux is however distinctly different from the ECMWF flux, which

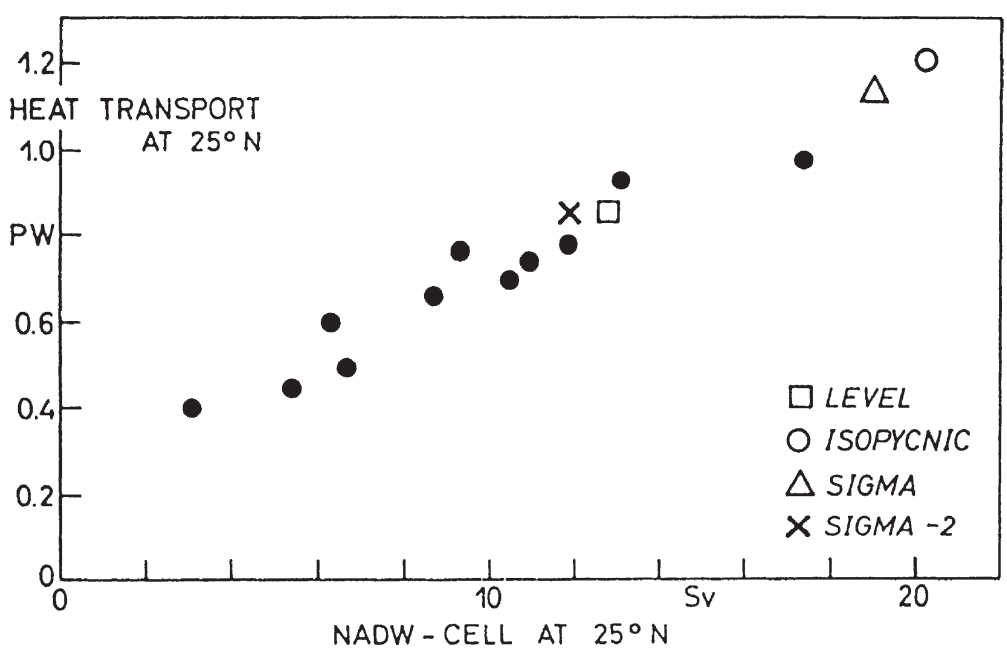

Fig. 10. Heat transport vs overturning at $25^{\circ} \mathrm{N}$ for the three intercomparison models and for SIGMA-2, together with a number of other model integrations discussed by Böning et al. (1996). 


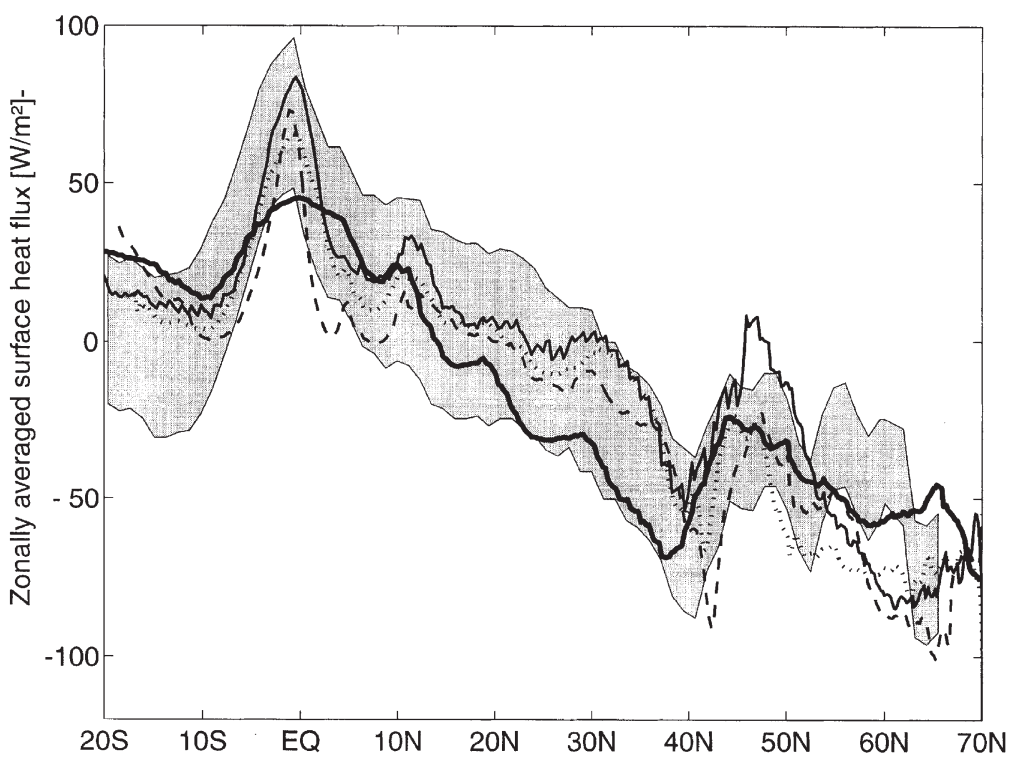

Fig. 11. Zonally averaged surface flux in $\mathrm{W} / \mathrm{m}^{2}$ vs. latitude, positive when ocean gains heat. Full thin line LEVEL, dashed ISOPYCNIC, dotted SIGMA. The heavy full line shows the flux from the ECMWF forcing. The shaded area corresponds to the climatological estimate by Hasse et al. (1996).

corresponds to an oceanic heat loss of $20-30 \mathrm{~W} / \mathrm{m}^{2}$. This difference is rather remarkable as the ECMWF data were used as forcing, and implies that the surface temperature of all models must be systematically colder than the SST from the forcing field (by $1-2^{\circ} \mathrm{C}$ ). In other words, none of the models is able to accommodate a substantial net heat loss through the surface. A heat loss of $25 \mathrm{~W} / \mathrm{m}^{2}$ is equivalent to a cooling trend of the upper $100 \mathrm{~m}$ of more than $10^{\circ} \mathrm{C}$ over 5 years. Unless the near-surface circulation in all models is substantially too weak, it appears that in this region the model estimates are more plausible than the ECMWF-climatology for 1986-89.

Near $40^{\circ} \mathrm{N}$ all models lose substantial amounts of heat, ranging from $50 \mathrm{~W} / \mathrm{m}^{2}$ in LEVEL to $90 \mathrm{~W} / \mathrm{m}^{2}$ in ISOPYCNIC. Near $45^{\circ} \mathrm{N}$, the heat loss is substantially reduced, and even turns into a weak gain in LEVEL. Here the quantitative differences between the models are large, and are associated with differences in their structures for the North Atlantic Current system (NAC) (see below). Around $60^{\circ} \mathrm{N}$ the models are again converge and feature a zonally averaged heat loss of $50-70 \mathrm{~W} / \mathrm{m}^{2}$ (in contrast both to the climatological as well as the ECMWF data) implying that at the surface all models are systematically warmer than the forcing SST.

The horizontal distribution of ocean-atmosphere energy flux (not shown) is likewise rather similar in all three models. All models show a small region of heat gain southeast of Newfoundland, in accordance with the ECMWF analysis. Only in LEVEL a secondary maximum of heat gain occurs at $50^{\circ} \mathrm{N}$ and $30-40^{\circ} \mathrm{W}$, an unrealistic feature that has been observed in many integrations with this model (e.g. Sarmiento, 1986) and is the result of the unrealistic pathway of the NAC in LEVEL (cf. following section). 


\subsection{Aspects of the horizontal circulation}

The mean sea-surface elevation (Fig. 12) gives an indication of the geostrophic component of the surface circulation. All three models perform rather similarly in terms of large-scale structure and magnitude, both in the subtropical/subpolar gyres and in the equatorial region, but differ on smaller scales and in several important regional features.

None of the three models is able properly to simulate the observed separation of the Gulf Stream at Cape Hatteras. This is expected since it is obvious that the resolution in all models remains too coarse to capture the details of the vorticity dynamics which control the separation process (Dengg, Beckmann \& Gerdes, 1996). Recent results demonstrate that both level and isopycnic models are able to simulate the Gulf Stream separation correctly at a resolution of $1 / 10^{\circ}$ or better (R. Bleck, R. Smith, pers. comm.).

The Gulf Stream path downstream of Cape Hatteras differs considerably in the three models. A strong recirculation is apparent in ISOPYCNIC (Fig. 12b) and also occurs to some extent in SIGMA (Fig. 12c). But it is absent in LEVEL, which instead shows an anticyclonic recirculation in the Mid-Atlantic Bight and indications of standing eddies (Fig. 12a), a pattern that has also
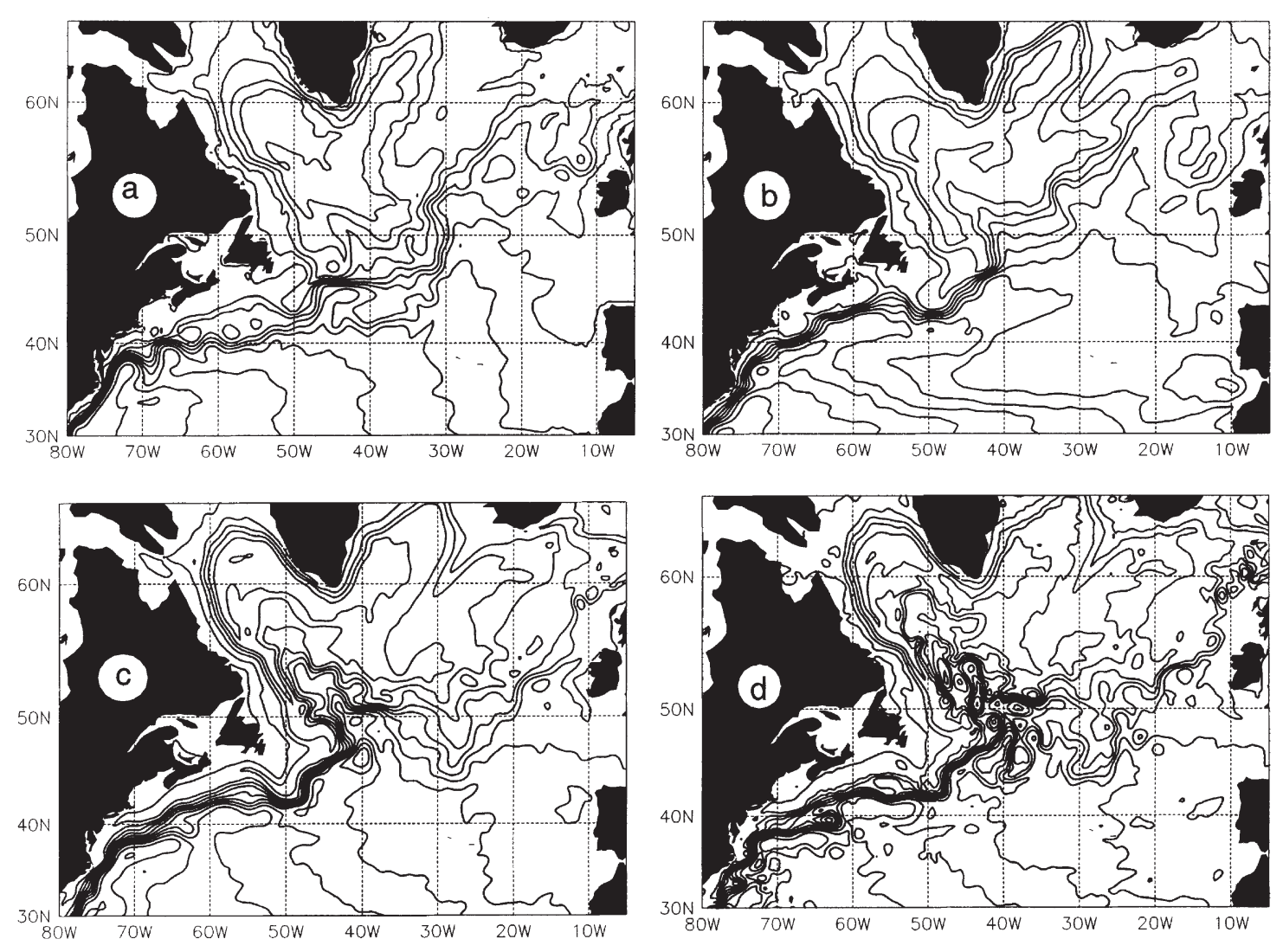

Fig. 12. Mean sea-surface elevation for LEVEL (a), ISOPYCNIC (b) and SIGMA (c), and an instantaneous seasurface elevation for SIGMA (d). Contour interval is $10 \mathrm{~cm}$. 
been observed in previous high-resolution simulations with the GFDL-model (Beckmann, Böning, Köberle \& Willebrand, 1994). In ISOPYCNIC one branch of that recirculation turns eastward, forming an eastward current that crosses the basin at $33^{\circ} \mathrm{N}$ and might be referred to as the model's 'Azores Current'. Its dynamical origin is related to the sinking and entrainment of Mediterranean Water, as shown by Jia (2000). A discussion of this model feature, which is absent from LEVEL and SIGMA but can also be seen in SIGMA-2, is given by New, Jia, Coulibaly and Dengg (2001).

While the flow of the Gulf Stream extension around the Grand Banks appears fairly realistic in all models, the pathways of the North Atlantic Current differ again. In ISOPYCNIC and SIGMA the NAC turns north at $42^{\circ} \mathrm{W}$ (Fig. 12b and Fig. 12c), and eastward again at $52-54^{\circ} \mathrm{N}$, with a branch towards the northwest which is particularly strong in SIGMA, reaching well into the Labrador Sea before turning back. In SIGMA, the currents in that region are for a large part eddy dominated, as can be seen from the snapshot in Fig. 12d. Warm eddies are generated off Flemish Cap and drift to the Northwest into the Labrador Sea. These eddies are intimately connected with the mean northward flow, and it is plausible that they may drive the mean flow, although this is an issue that needs further study. The signature of these eddies is also seen in the variability of the sea level elevation (Fig. 16c below).

It appears that the strong topographic smoothing used in the basic SIGMA experiment resulted in a bottom depth, which over the Grand Banks of Newfoundland and Flemish Cap Banks, is two to four times greater than in reality. Consequently the amount of cold water stored over the Banks is far too large and extends too deeply, thus increasing the available potential energy in the frontal system of the North Atlantic current and local generation of mesoscale eddies. In addition, it is likely that the strength of the recirculating transport cells observed in this area in SIGMA (cf. the discussion of Fig. 14 below) is directly related to these enhanced conditions of instability. This feature is also present in the SIGMA-2 experiment, but has been reduced by the use of a more realistic (less smoothed) topography in this region, and hence in a reduction of available potential energy.

In LEVEL (Fig. 12a), the main part of the NAC is deflected eastward south of Flemish Cap and continues until $30^{\circ} \mathrm{W}$ where it finally turns north, a behaviour which clearly deviates from the observed NAC pathway as described e.g. by Käse and Krauss (1996). The failure to simulate the correct pathway of North Atlantic Current causes the erroneous surface heat budget in LEVEL discussed above, and is also responsible for problems in the path of the Deep Western Boundary Current and in the eddy energy. Results from earlier CME experiments, as well as from other high-resolution simulations with MOM (e.g. Stammer et al., 1996) indicate a high sensitivity of the NAC to details of the topographic structure near Flemish Cap and Flemish Pass.

The different pathways of the NAC are most clearly seen in the 5-year mean sea surface height at $48^{\circ} \mathrm{N}$ (Fig. 13). SIGMA shows a strong recirculation, with a steep SSH increase of nearly $80 \mathrm{~cm}$ over $200 \mathrm{~km}$ associated with northward flow, a decrease of $55 \mathrm{~cm}$ between $40^{\circ} \mathrm{W}$ and $30^{\circ} \mathrm{W}$, and a weaker northward flow around $25^{\circ} \mathrm{W}$. Such strong recirculation is, however, absent in SIGMA-2 where the main front at $42^{\circ} \mathrm{W}$ is much weaker $(35 \mathrm{~cm})$, followed by a more gentle increase extending to $30^{\circ} \mathrm{W}$ where the flow remains northward. The main front in ISOPYCNIC is at the same longitude, with some $50 \mathrm{~cm}$ SSH difference, and otherwise not unlike SIGMA-2. In LEVEL the main front has similar strength $(50 \mathrm{~cm})$ but is located about $10^{\circ}$ farther to the east near $30^{\circ} \mathrm{W}$. An estimate of the mean sea level based on hydrographic observations and satellite altimetry west of $30^{\circ} \mathrm{W}$ has been given by Singh and Kelly (1997), and is discussed in Killworth, 


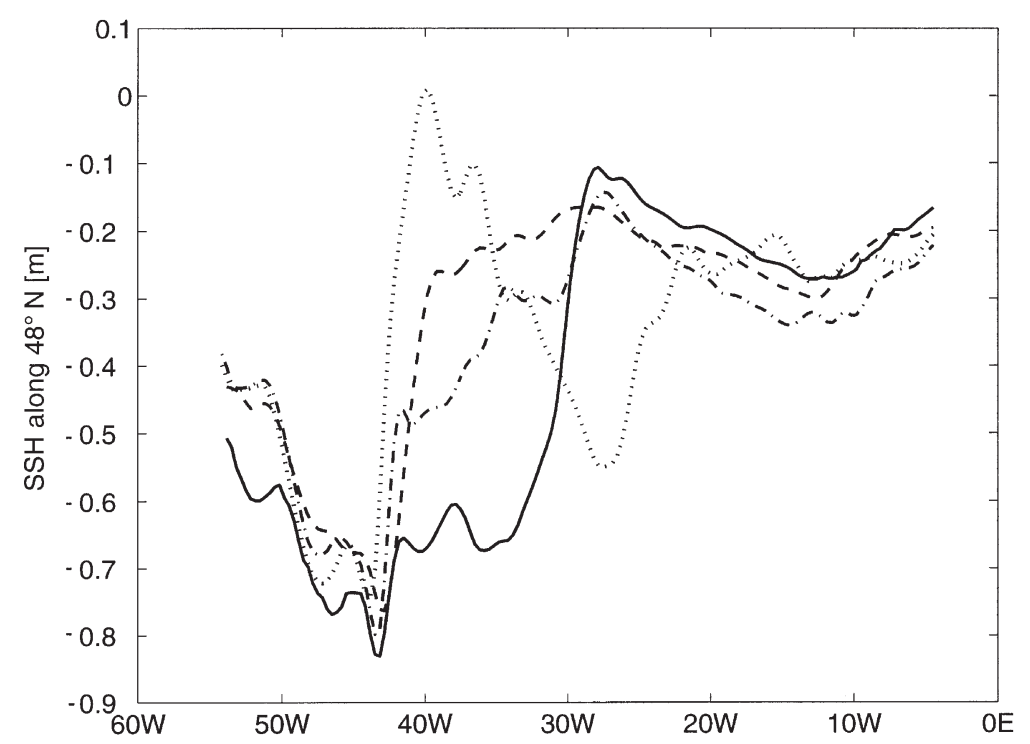

Fig. 13. Mean surface elevation along $48^{\circ} \mathrm{N}$ for different models. Full line: LEVEL, dashed: ISOPYCNIC, dotted: SIGMA, dash-dotted: SIGMA-2.

Dieterich, Molines, Oschlies and Willebrand (2001). Of the four simulations, SIGMA is by far in best agreement with these observations, followed by ISOPYCNIC and SIGMA-2, whereas LEVEL performs rather poorly here. All three models have however a fairly similar SSH decrease around $50^{\circ} \mathrm{W}$, associated with the Labrador Current.

A different view of the overall horizontal circulation pattern is provided by the vertically integrated transport which is often an expression of the circulation in the upper kilometer. The interpretation of this variable is in itself not always straightforward as it constitutes a sum of flows that may have quite different origin and dynamics. In contrast, the interpretation of the differences between the three models is conceptually easier as they must be caused by different baroclinic flows in connection with the bottom topography which, apart from small frictional and nonlinear effects, constitute the only way a model can deviate from the flat-bottom Sverdrup balance.

The 5-year mean barotropic streamfunction for the three models (Fig. 14) has a rich structure, with much of the barotropic transport confined to rather narrow regions near the continental shelf break. All models have well-developed gyres of roughly similar structure and magnitude, reaching approximately $30 \mathrm{~Sv}$ in the subpolar gyre south of Cape Farewell, and 30-35 Sv in the Gulf Stream at $25^{\circ} \mathrm{N}$. On smaller scales, however, there are significant differences between the models.

In the regions of high eddy activity, i.e. the Gulf Stream and North Atlantic Current regions, numerous closed recirculation cells are found which are strongest by far in SIGMA, weaker in LEVEL and almost absent in ISOPYCNIC. In particular, SIGMA displays a series of rather strong transport cells northeast of the Grand Banks. The strengths of these recirculating barotropic flows are considerably weaker in the experiment SIGMA-2 with less smoothed topography (not shown), thus a realistic representation of the topography is a key element in realistically simulating the flow pattern in this region. Note that the barotropic circulation component usually is poorly 

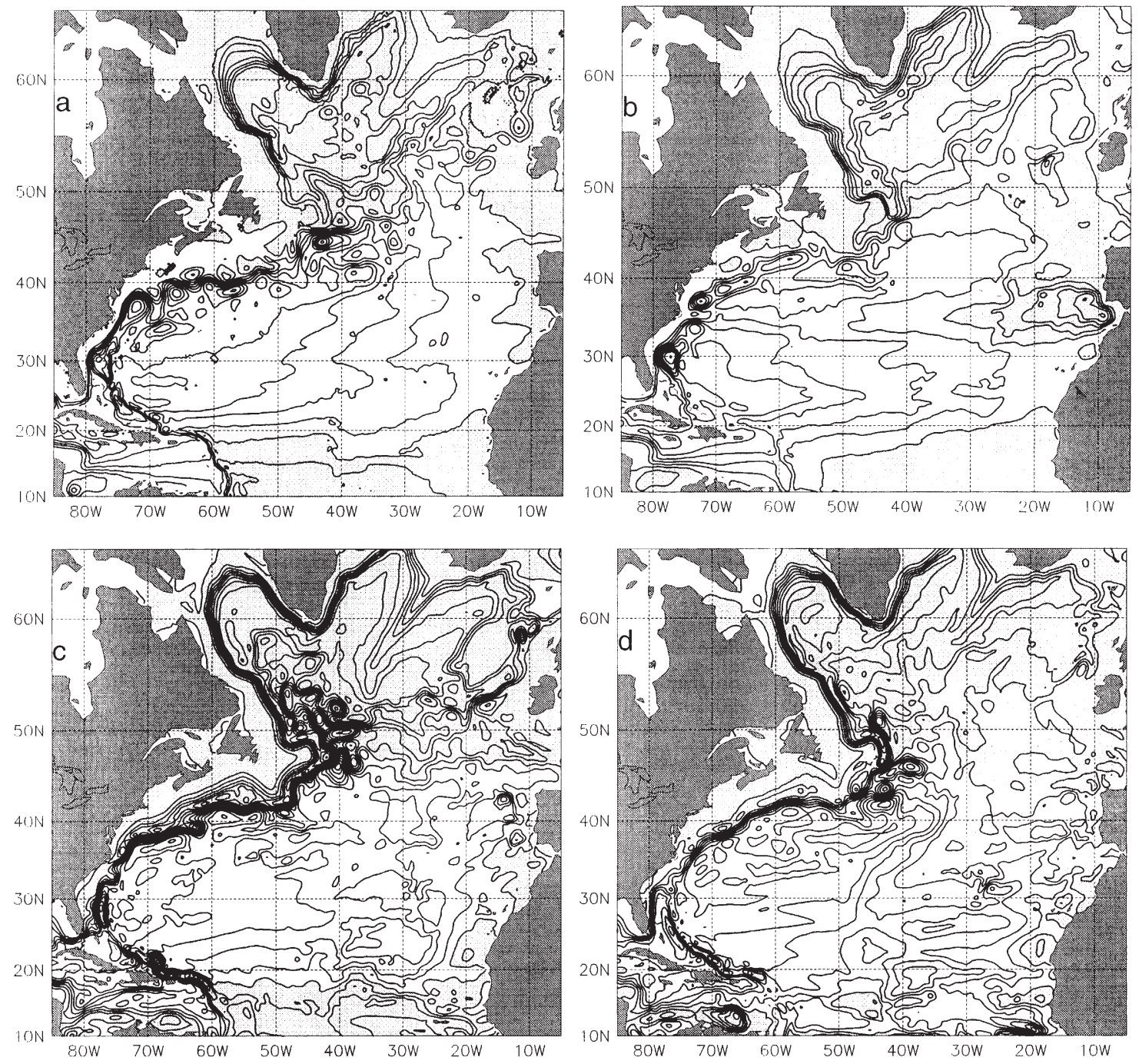

Fig. 14. Streamfunction of vertically integrated transport. a) LEVEL, b) ISOPYCNIC, c) SIGMA, d) SIGMA-2. Contour interval $5 \mathrm{~Sv}$. Shaded regions correspond to negative values.

observed, and there is some evidence that the presence of small barotropic recirculation structures might not be unrealistic (Rossby, 1996; T. Sanford, 1998, pers. comm.).

ISOPYCNIC (Fig. 14b) exhibits a cyclonic cell off Gibraltar, which has a diameter of more than $1000 \mathrm{~km}$ and reaches a magnitude exceeding $20 \mathrm{~Sv}$. This feature appears rather unrealistic and is clearly inconsistent with a Sverdrup balance which at $36^{\circ} \mathrm{N}$ can be expected to hold at least in the eastern basin. As discussed by Jia (2000), it is caused by a problem with the relaxation condition applied in the area off Gibraltar to simulate Mediterranean Water, in connection with the use of potential density $\sigma_{\theta}$.

At the latitude $25^{\circ} \mathrm{N}$, it is commonly assumed that the vertically integrated transport is governed by a flat-bottom Sverdrup balance to a good approximation, at least in the eastern basin. In Fig. 
15, it can be seen that this is only the case for LEVEL. In SIGMA there is a strong deviation from Sverdrup balance in the eastern basin, with a boundary current occurring east of the MidAtlantic Ridge. This current is associated with an anticyclonic gyre between $20^{\circ} \mathrm{W}$ and $40^{\circ} \mathrm{W}$, which reaches a transport of $10 \mathrm{~Sv}$ (see also Fig. 14c). This behaviour must result from the interaction of baroclinic flows with topography. Near-bottom flows in SIGMA are much more intense than in the other two models. This anticyclonic gyre likewise occurs in SIGMA-2 (though somewhat weaker). Whether or not it is a realistic feature is unclear as there are no conclusive direct transport observations in this region. However, it is possible that the smoothing of the topography in SIGMA that widens most topographic features is increasing the overall importance of the topographic constraint in the integrated vorticity balance.

The southward transport in ISOPYCNIC west of $30^{\circ} \mathrm{W}$ systematically exceeds the value suggested from the Sverdrup balance. As seen from Fig. 8, this is related to stronger southward flow in the deep interior, compared to the other models. Interaction of baroclinic flow with bottom topography is unlikely to be the cause as the deviations appear to be unaffected by the MidAtlantic Ridge. The origin of this behaviour can be traced to the use of a potential density in ISOPYCNIC. As the mean SSH distribution for all three Dynamo models at $25^{\circ} \mathrm{N}$ outside of the boundary currents is very similar, and the Ekman components are identical, any differences must be associated with the baroclinic transport relative to the surface. From an integration of the thermal wind balance, it then follows that the difference in the vertically integrated meridional volume transport $M^{(y)}$ e.g. between ISOPYCNIC and LEVEL is given by

$$
\Delta M^{(y)}=\int_{-H}^{0}\left(v_{\text {iso }}-v_{\text {lev }}\right) \mathrm{d} z=\frac{g}{f} \int_{-H}^{0}[z+H]\left[\frac{\partial \rho_{\text {iso }}}{\partial x}-\frac{\partial \rho_{\text {lev }}}{\partial x}\right] \mathrm{d} z
$$

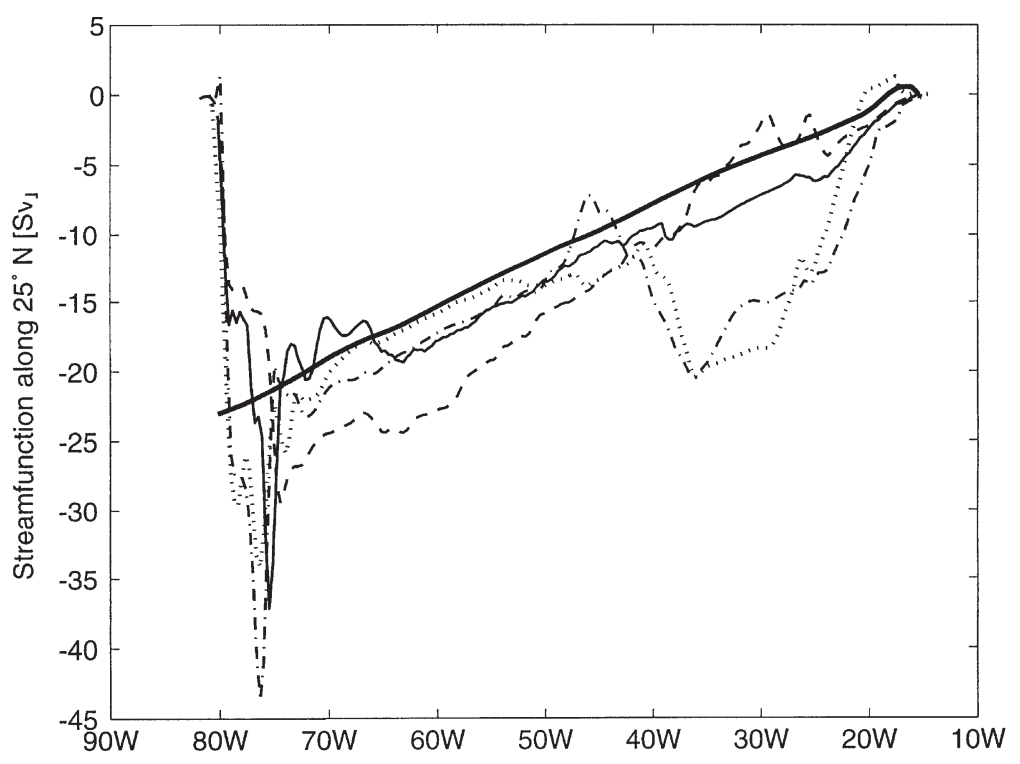

Fig. 15. Vertically integrated transport for all models at $25^{\circ} \mathrm{N}$. Full thin line LEVEL, dashed ISOPYCNIC, dotted SIGMA, dash-dotted SIGMA-2. The heavy full line corresponds to the Sverdrup transport derived from the ECMWF forcing common to all models. 
The difference in the horizontal density gradients results mainly from the increase with pressure of the thermal expansion coefficient which is not accounted for in ISOPYCNIC. At $25^{\circ} \mathrm{N}$ the temperature generally decreases towards the east, therefore the sign of $\Delta M^{(y)}$ is generally negative. The interior barotropic flow in ISOPYCNIC is therefore expected to be systematically more southward than in LEVEL. By integration of Eq. (5) at $25^{\circ} \mathrm{N}$ across the basin from the eastern boundary $x_{\mathrm{E}}$ to a location $x_{\mathrm{W}}$ just outside the western boundary current, the total transport difference is found to be $\int_{\mathrm{x}_{\mathrm{W}}}^{x_{\mathrm{E}}} \Delta M^{(y)} \mathrm{d} x \approx-12.05 \mathrm{~Sv}$. This magnitude is consistent with the $x_{\mathrm{W}}$ results shown in Fig. 15 and Fig. 8. It seems likely that the use of a modified equation of state in the isopycnal model as introduced by Sun et al. (1999) would largely reduce this difference.

\subsection{Eddy variability}

The mesoscale eddy variability is largely responsible for processes of baroclinic and barotropic instability, at least in the extratropics. Differences in the eddy activity in the three models will therefore reflect differences in the mean circulation. We will focus here only on those aspects of the models' variability which helps to identify deficiencies in the simulations.

The sea surface height variability for the three models, averaged over the 5 years of the intercomparison experiments, is shown in Fig. 16. Results from the Community Modeling Effort and from other studies have demonstrated that a horizontal resolution of $1 / 3^{\circ}$ is insufficient to provide a realistic simulation of mesoscale variability. Hence it is not surprising that the eddy activity in all three models is lower than observed. The amplitudes of eddy activity in LEVEL and SIGMA are similar to those in previous $1 / 3^{\circ} \mathrm{CME}$ experiments (see, e.g., Treguier, 1992). LEVEL is the best of the models in simulating the magnitude of SSH variability in the Gulf Stream region, with values between $20 \mathrm{~cm}$ and $30 \mathrm{~cm}$ rms. The amplitude is somewhat lower in SIGMA $(10 \mathrm{~cm}$ to $25 \mathrm{~cm} \mathrm{rms}$ ), and much lower in ISOPYCNIC (below $15 \mathrm{~cm} \mathrm{rms).} \mathrm{These} \mathrm{values} \mathrm{need} \mathrm{to} \mathrm{be}$ compared to more than $30 \mathrm{~cm}$ rms observed in altimetric data. The corresponding values for eddy kinetic energy (EKE) reach values above $1000 \mathrm{~cm}^{2} / \mathrm{s}^{2}$ in LEVEL and SIGMA, and around $250 \mathrm{~cm}^{2} / \mathrm{s}^{2}$ in ISOPYCNIC.

The lack of variability in ISOPYCNIC had not been expected, since this model is conceptually well suited to simulate adiabatic instability processes. Analysis revealed that the eddy potential energy is similar in magnitude to those in the other models, and the conditions for baroclinic instability are likewise potentially favourable (see D97). Hence the reason for the low eddy activity must lie in the dissipation, and results mainly from the different parametrization of horizontal friction in ISOPYCNIC. As described above, the lateral dissipation coefficients were chosen such that all models have identical friction at the grid scale, except in regions of strong currents. At the eddy scale $L_{\mathrm{e}}$ of typically several gridpoints, the dissipation by the Laplacian friction operator in ISOPYCNIC therefore is higher by a factor $L_{\mathrm{e}}^{2} / \Delta_{x}^{2}$ than that of the more scale-selective biharmonic parametrization in the other two models. In addition, instability primarily occurs in regions of high Rossby number where the shear-dependent increase of friction in ISOPYCNIC becomes effective, leading to a further dampening of model variability. A further reason could be in the mixed-layer formulation in ISOPYCNIC. The removal of wind-induced vertical shear by vertical homogenization of momentum has an effect similar to that of a large vertical friction 

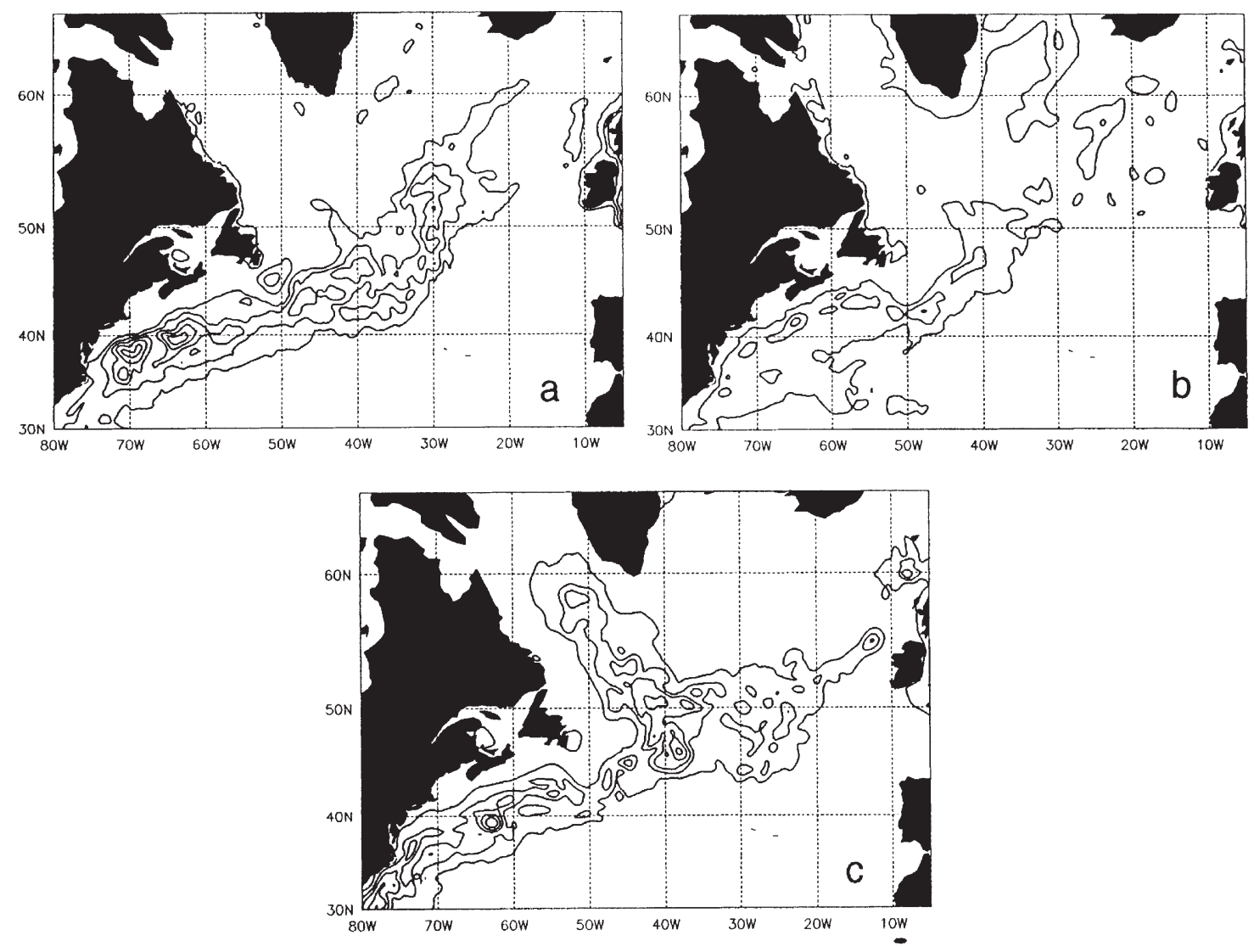

Fig. 16. Variability (rms) of the sea level elevation, for a) LEVEL, b) ISOPYCNIC and c) SIGMA. Contour interval $5 \mathrm{~cm}$.

which generally acts as a dissipation of potential energy (Gent, Willebrand, McDougall \& McWilliams, 1995). This factor could however contribute to lower EKE-values only at mid and high latitudes where the mixed layer can be several hundred meters deep in winter, but not in the tropics where the mixed layer remains very shallow.

The horizontal distribution of rms sea surface height (Fig. 16) is closely related to that of the near-surface eddy kinetic energy (EKE, not shown). The distribution of rms SSH in the three models reflects the differences in the pathway of the North Atlantic Current that have been discussed above. All models show high variability along the main path of the Gulf-Stream and to the east of the Grand Banks. Differences exist not only in the magnitude but also in the patterns, allowing some inference for the eddy generation mechanims (see D97, and also Barnier et al., 2001).

Another region of high variability is the North Atlantic Current where all models show large variability east of the Grand Banks along the path of the NAC. While energy levels are low in ISOPYCNIC, the mean pattern is consistent with the path of the NAC around the Banks as its turn to the east. In SIGMA and LEVEL, EKE levels are higher and more consistent with observations derived from ERS-1 (Heywood, McDonagh \& White, 1994), with values above $500 \mathrm{~cm}^{2} / \mathrm{s}^{2}$ 
between $45^{\circ} \mathrm{N}$ and $52^{\circ} \mathrm{N}$, and locally above $1000 \mathrm{~cm}^{2} / \mathrm{s}^{2}$ in SIGMA. However, it is in this region that there are the largest discrepancies in the distribution of eddy energy, both between the three models and also between the models and observations. In LEVEL, an area of high variability extends from the Grand Banks to the Mid-Atlantic Ridge (MAR) between $40^{\circ} \mathrm{N}$ and $50^{\circ} \mathrm{N}$, and over the MAR along $30^{\circ} \mathrm{W}$. The EKE in this region reaches a maximum over $500 \mathrm{~cm}^{2} / \mathrm{s}^{2}$ on the eastern flank of the ridge. This unrealistic feature is clearly a consequence of the likewise unrealistic pathway of the NAC in LEVEL which has been discussed above.

In SIGMA, eddy variability is found to be high from Flemish Cap to the Mid-Atlantic Ridge, with the branches of the NAC. However, unlike the other models, SIGMA has an unexpected high variability in the Labrador Sea, a feature that is not supported by any observations. A detailed look at the flow characteristics in this region reveals the following picture: the extension of the Gulf Stream after it reaches the Newfoundland Ridge takes the shape of a large inertial recirculation cell, which extends from Flemish Cap to the MAR. This cell is marginally stable and periodically grows and then breaks into a large number of very energetic mesoscale eddies which drift to the northwest into the Labrador Sea. These eddies are very coherent in the vertical and have a lifetime of more than a year, and their signature is not smoothed out in the 5-year mean streamfunction (cf. Fig. 12 and Fig. 14). As a consequence, these eddies bring warm and salty subtropical waters into the Labrador Sea. As discussed in Section 3.4, this is related to the large potential energy caused by the strong smoothing off Flemish Cape. It may also be a consequence of the stability of the jet which appears different from the other models, in relation to the presence of the cyclonic circulation cell near the Grand Banks. It is unlikely, however, that the local topographic control of the flow is responsible, because the feature occurs in deep waters.

There are very few regions where some of the models overestimate variability. In the Florida Current, SIGMA has a variability of $20 \mathrm{~cm} \mathrm{rms,} \mathrm{whereas} \mathrm{altimetric} \mathrm{data} \mathrm{show} \mathrm{only} 10 \mathrm{~cm} \mathrm{rms.}$ The explanation is that the change in topography caused by the smoothing has increased the depth to $500 \mathrm{~m}$ in SIGMA, and the Florida Current oscillates between positions east or west of the Banks. This unrealistic oscillation generates meanders in the stream which propagate northward, and are largely responsible for the high variability observed in SIGMA off the coast of the southeastern US. This behaviour has been fully corrected by the inclusion of the Bahamas island in SIGMA-2. Another example is a maximum of the rms SSH in ISOPYCNIC in the Irminger and Labrador Currents, a pattern not seen in the altimetric data nor in the other models.

\section{Summary and conclusions}

An intercomparison between three realistic eddy-permitting ocean models for the North Atlantic circulation has been performed, with the objective of finding the sensitivity of model results to the different representations of critical physical processes. All three models have been able to simulate the large-scale characteristics of the North Atlantic circulation with a fair degree of realism, but our interest has been to discover where and why the models differ from each other and/or from the observations. While these differences are substantial in some important aspects, generally they are not larger than differences within one model when run under slightly modified conditions.

Of fundamental importance is the conclusion that the large-scale thermohaline circulation is 
strongly influenced by rather localised processes; in particular by the overflow crossing the Greenland-Scotland region, their water mass properties, and the details of mixing within a few hundred kilometers south of the sills. Much of the large-scale differences between the three models with respect to deep circulation and large-scale transports are ultimately generated by the differences in their representations of the processes in this relatively small region. For simulations over longer time scales, these differences would translate into differences in water mass composition. For the correct simulation of decadal changes involving the thermohaline circulation, accurate representation (either explicitly or parametrically) of the overflows and their associated mixing processes seems imperative.

Another area where a local process has large-scale implications, is the sensitivity to small-scale details of the bathymetry. For instance, the pathway of the North Atlantic Current off Flemish Cap is strongly influenced by details of topography and/or geometry, as shown by the differences between the two SIGMA experiments. The mechanisms are not fully understood, and are probably not identical in the different models. In LEVEL the most likely cause is the staircase representation of topography in connection with insufficient resolution; in integrations with a resolution of $1 / 10^{\circ}$ this problem no longer occurs (Bryan \& Smith, 1998). In SIGMA the problem most likely lies in the topographic smoothing, as discussed above.

Near the surface, the agreement between the three models is fairly close with respect to sea surface temperature and heat flux fields. Although the atmospheric forcing has been applied in a self-consistent way, systematic deviations from the forcing fields occur in some regions, in particular over much of the subtropical gyre. Obviously, in this region the atmospheric forcing is inconsistent with upper ocean dynamics in the three integrations.

All models share the problem that the resolution, which ranges from $37 \mathrm{~km}$ at the equator to $13 \mathrm{~km}$ at $70^{\circ} \mathrm{N}$, is insufficient fully to resolve the mesoscale eddy field. This causes common problems, such as e.g. the lack of proper separation of the Gulf Stream or in the marginal resolution of the Deep Western Boundary Current. The eddy energy is generally too low, and its distribution differs somewhat from observed patterns and is very much correlated with the path of strong mean flows.

More informative than the areas of agreement are those where models develop problems, and so disagree with each other or fail to reproduce observed patterns. This is where the main benefits of the intercomparison accrue, through learning what causes the problems, and how they may ultimately be resolved. In the following, the performance of the three models is briefly summarised.

The most glaring deficiency of the LEVEL model, which the present experiment shares with many previous implementations of such models, is in the simulation of vertical overturning and the related meridional transport of heat. Excessive diapycnal mixing, which is induced by the numerical algorithms and also through the staircase representation of topography, tends to occur primarily in regions of strong topographic or isopycnal slopes and affects the integrity of water masses in this model. In particular, this applies to the overflows, which seem to be less well represented than in the other models. To a lesser extent this applies also to the Gulf Stream region where LEVEL has a strong upwelling limiting its meridional transports. A specific regional problem of LEVEL is its failure to simulate the correct pathway of the North Atlantic Current. This error has significant consequences for heat budget, eddy energy and also the deep boundary current. 
For the future development of LEVEL models, reductions in unphysical diapycnal mixing must have the highest priority. The simulation of near-bottom flows can probably be improved through specific bottom-boundary-layer modules (Beckmann \& Döscher, 1997; Killworth \& Edwards, 1999). In particular, mixing in overflows could be better controlled in this way. Even in models that resolve eddies, some dissipation is necessary to ensure numerical stability. Replacing horizontal biharmonic diffusion by a dissipation scheme which avoids unphysical diapycnal transports, (as suggested by Gent and McWilliams, 1990, for eddy parametrization in coarse-resolution models) could be a promising route.

Isopycnal models are particularly suitable for the simulation of flows along isopycnal surfaces, and diapycnal mixing, which corresponds to flow across these surfaces, can be added in a controlled form. Not surprisingly, it appears that some aspects of the circulation in the upper kilometer are represented more realistically by ISOPYCNIC than in the other two models. ISOPYCNIC has performed comparatively well in simulating the formation and outflow of deep water masses, and has not suffered from too much diapycnal mixing in the formation regions. Conversely in some regions the mixing rate has been rather too small. It is a very rare situation for an ocean modeller to find that more, rather than less, mixing is needed. Increasing the mixing would not be difficult, and would be likely to improve the simulation, particularly if that increase were to be restricted to areas with strong shear or rough topography where diapycnal mixing appears to be strongest (Polzin, Toole, Ledwell \& Schmitt, 1997). ISOPYCNIC also appears to be less sensitive to smallscale topographic variations, as the layer structure inhibits the development of strong vertical motions.

Inevitably, the isopycnal concept has some inherent drawbacks, the most obvious being the fact that the use of a single potential density both for layer definition and for baroclinic pressure gradient is dynamically inconsistent. This problem cannot be cured by the usual resort of numerical modellers, i.e. to increase the resolution. The problem is apparent in the present model's inability to simulate the circulation and water mass distribution associated with the AABW, and in systematic deviations from the thermal wind relation, which is for example responsible for its systematic deviation from the Sverdrup balance in the subtropical gyre. Choice of a different reference pressure (e.g., 2000 dbar instead of surface) could reduce problems in the deep ocean but would create significant errors in the upper ocean. This deficiency of isopycnal models has long been recognised, but only recently there have been developments that may largely reduce it (Sun et al., 1999; Eden \& Willebrand, 1999).

Another problem of ISOPYCNIC lies in the mixed layer formulation, more precisely its inability to permit shear in the mixed layer, even if that is very deep. The suppression of vertical shear could also be one cause of its eddy energy being far too low. The choice of harmonic lateral diffusion, rather than biharmonic as in the other models, may also contribute to lower eddy energy. Other specific problems of ISOPYCNIC, such as e.g. the unrealistic behaviour around the Mediterranean Water inflow, are more regional and could probably be fixed by more tuning or sensitivity studies. Also, the diapycnal transports induced by nonlinearities in the equation of state (cabbeling and thermobaricity), which are absent from the present implementation, can in principle be included (McDougall \& Dewar, 1998).

A model in which a coordinate surface coincides with the sea floor topography is most suitable where the topographic influence is the dominant factor, as borne out by meteorological experience with terrain-following coordinates. Generally speaking, the deep circulation in SIGMA is more 
vigorous than in the other models, especially in the deep ocean. One possible reason is that SIGMA effectively may have less bottom friction than the other two models. Although the coefficients in the bottom stress parameterisation (Eq. (2)) are identical in all models, SIGMA does not have an additional dissipation of vorticity in the sidewall boundary layer generated by the no-slip condition at every stair case (de Miranda, Barnier \& Dewar, 1999). The deep circulation in the subpolar gyre appears to be more topographically controlled and more coherent than in the other models. A number of closed circulation gyres are visible in the barotropic streamfunction which are absent from the other models. These appear less plausible when occuring on large scale, as e.g. in the eastern basin in the subtropical gyre, although it would be consistent with a southward flow at the bottom on the eastern flank of the Mid-Atlantic Ridge, in relation with a possible cyclonic deep circulation in the ocean basins (Bogden, Davis \& Salmon, 1993; Eby \& Holloway). At smaller scales, barotropic recirculation gyres may actually exist in parts of the ocean (but would be difficult to observe).

The unrealistic aspect of the circulation in the Labrador Sea apparently has its origin in the topographic control of the North Atlantic Current in connection with an overly smooth topography. The consequences for the local circulation are quite dramatic. In SIGMA-2 this problem is much reduced, but at the expense of a deterioration in other aspects of the simulation. The formulation of the lateral diffusion along geopotential surfaces leads to unphysical mixing across density surfaces, in particular in regions of strong differences between topographic and isopycnal slopes. For this reason, there is too much mixing in the overflow region, much like in LEVEL, and the potential strength of the SIGMA model has not been realised. It should however be noted that the application of this type of coordinate to simulate the ocean circulation at basin scale is still in an early stage, and that more experience needs to be built up to master the smoothing of the bottom topography in relation with the calculation of the horizontal pressure gradient.

In conclusion we remark that all three models have shown substantial deficits, and no single model excels in all relevant aspects. The question of which model is 'best' is therefore largely irrelevant. What is important, however, is to realise that even in these models of relatively high resolution the proper representation of certain physical processes, including small-scale processes such as the overflows, is crucial to obtain the correct large-scale behaviour. It is obvious that similar sensitivities must also exist in models of lower resolution, e.g. in the ocean components of climate models. We hope that our study has helped to clarify some critical model aspects which future developments can concentrate on.

\section{Acknowledgements}

The work reported in this paper is part of the project 'DYNAMO' which has been supported by the European Union Marine Science and Technology programme under contract no. MAS2CT93-0060. This support is gratefully acknowledged. We would like to thank our colleagues S. Barnard, A. Beckmann, J. Blundell, M. Coulibaly, D’Arcy de Cuevas, J. Dengg, P. Herrmann, M.-M. Lee, A. Oschlies, R. Redler, T. Reynaud and A. Schiller who contributed to various stages of the project. We also acknowledge the provision of supercomputing facilities by the Rechenzentrum der Universität Kiel, Deutsches Klimarechenzentrum Hamburg, the Atlas Centre at the Rutherford Appleton Laboratory, and the Institut pour le Développement des Ressources en Informatique Scientifique, Centre National de la Recherche Scientifique. 


\section{Appendix A}

The central depths of the 31 tracer levels in the LEVEL-model are (in m) 18, 53, 92, 133, 180, $233,295,370,463,577,721,901,1125,1375,1625,1875,2125,2375,2625,2875,3125,3375$, $3625,3875,4125,4375,4625,4875,5125$ and 5375 .

The densities $\left(\sigma_{\theta}\right)$ of the 19 isopycnal layers in the ISOPYCNIC-model, underlying a mixed layer of variable density, are 24.70, 25.28, 25.77, 26.18, 26.52, 26.80, 27.03, 27.22, 27.38, 27.52, 27.64, 27.74, 27.82, 27.88, 27.92, 28.00, 28.06, 28.09 and 28.12.

At a depth of $1000 \mathrm{~m}$, the 20 tracer levels in the SIGMA-model correspond to 21 levels for the vertical velocity which are given by $0,13,27,43,61,82,110,145,189,241,299,360,420$, 476, 531, 585, 643, 709, 787, 882 and $1000 \mathrm{~m}$. At other depths, these levels change proportionally.

\section{References}

Anderson, D. L. T., Bryan, K., Gill, A. E., \& Pacanowski, R. C. (1979). Ocean response to low-frequency wind forcing with application to the seasonal variation in the Florida Straits-Gulf Stream transport. Journal of Geophysical Research, 84, 4795-4815.

Baringer, M. O., \& Price, J. F. (1997). Mixing and spreading of the Mediterranean outflow. Journal of Physical Geography, 27, 1654-1677.

Barnier, B., Marchesiello, P., de Miranda, A. P., Molines, J. M., \& Coulibaly, M. (1998). A sigma-coordinate primitive equation model for studying the circulation in the South Atlantic. Part I: model configuration with error estimates. Deep Sea Research I, 45, 543-572.

Barnier, B., Reynaud, T., Beckmann, A., Böning, C., Molines, J.-M., Barnard, S., \& Jia, Y. (2001). On the seasonal variability and eddies in the North Brazil Current: insights from model intercomparison experiments. Progress in Oceanography, 48, 195-230.

Barnier, B., Siefridt, L., \& Marchesiello, P. (1995). Thermal forcing for a global ocean circulation model using a threeyear climatology of ECMWF analyses. Journal of Marine Systems, 6, 363-380.

Beckmann, A., Böning, C. W., Köberle, C., \& Willebrand, J. (1994). Effects of increased horizontal resolution in a simulation of the North Atlantic Ocean. Journal of Physical Oceanography, 24, 326-344.

Beckmann, A., \& Döscher, R. (1997). A method for improved representation of dense water spreading over topography in geopotential-coordinate models. Journal of Physical Oceanography, 27, 581-591.

Bleck, R., Hanson, H. P., Hu, D., \& Kraus, E. B. (1989). Mixed layer-thermocline interaction in a three-dimensional isopycnic coordinate model. Journal of Physical Oceanography, 19, 1417-1439.

Bleck, R., Rooth, C., Hu, D., \& Smith, L. T. (1992). Salinity-driven thermocline transients in a wind- and thermohalineforced isopycnic coordinate model of the North Atlantic. Journal of Physical Oceanography, 22, 1486-1505.

Bogden, PH. S., Davis, R. E., \& Salmon, R. (1993). The North Atlantic Circulation: combining simplified dynamics with hydrographic data. Journal of Marine Research, 51, 1-52.

Böning, C. W., \& Bryan, F. O. (1996). Large-scale transport processes in high-resolution circulation models. In W. Krauss, The warmwatersphere of the North Atlantic Ocean (pp. 91-128). Berlin, Stuttgart: Gebrüder Bornträger.

Böning, C. W., Bryan, F. O., Holland, W. R., \& Döscher, R. (1996). Deep-water formation and meridional overturning in a high-resolution model of the North Atlantic. Journal of Physical Oceanography, 26, 1142-1164.

Böning, C. W., Holland, W. R., Bryan, F. O., Danabasoglu, G., \& McWilliams, J. C. (1995). An overlooked problem in model simulations of the thermohaline circulation and heat transport in the Atlantic Ocean. Journal of Climate, $8,515-523$.

Bryan, K. (1969). Climate and the ocean circulation. III: The ocean model. Monthly Weather Review, 97, 806-827.

Bryan, F. (1987). Parameter sensitivity of primitive equation ocean general circulation models. Journal of Physical Oceanography, 17, 970-985.

Bryan, F., \& Smith, R. (1998). Modelling the North Atlantic Circulation: from eddy-permitting to eddy-resolving. WOCE Newsletter, 33 (unpublished manuscript), 12-44. 
Chassignet, E. P., Smith, L. T., Bleck, R., \& Bryan, F. O. (1996). A model comparison: numerical simulations of the north and equatorial Atlantic oceanic circulation in depth and isopycnic coordinates. Journal of Physical Oceanography, 26, 1849-1867.

Cox, M. D. (1984). A primitive equation, 3-dimensional model of the ocean. GFDL Ocean Group Technical Report No. 1, GFDL, Princeton University.

Dengg, J., Beckmann, A., \& Gerdes, R. (1996). The Gulf Stream Separation Problem. In W. Krauss, The Warmwatersphere of the North Atlantic Ocean (pp. 253-290). Berlin, Stuttgart: Gebrüder Bornträger.

Dickson, R. R., \& Brown, J. (1994). The production of North Atlantic Deep Water: sources, rates, and pathways. Journal of Geophysical Research, 99, 12319-12341.

Didden, N., \& Schott, F. (1991). Seasonal variations in the western tropical Atlantic: surface circulation from Geosat altimetry and WOCE model results. Journal of Geophysical Research, 97, 3529-3541.

Döscher, R., Böning, C. W., \& Herrmann, P. (1994). Response of circulation and heat transport in the North Atlantic to changes in thermohaline forcing in northern latitudes: a model study. Journal of Physical Oceanography, 24, 2306-2320.

Döscher, R., \& Redler, R. (1997). The relative influence of North Atlantic overflow and subpolar deep convection on the thermohaline circulation in an OGCM. Journal of Physical Oceanography, 27, 1894-1902.

Döös, K., \& Webb, D. J. (1994). The Deacon cell and other meridional cells of the Southern Ocean. Journal of Physical Oceanography, 24, 429-442.

DYNAMO Group (1997). DYNAMO: dynamics of the North Atlantic Models: simulation and assimilation with highresolution models. Ber. Institut für Meereskunde, Universität Kiel, 294, 334 pp.

Eby, M., \& Holloway, G. (1994). Sensitivity of a large-scale ocean model to a parameterization of topographic stress. Journal of Physical Oceanography, 24, 2577-2588.

Eden, C., \& Willebrand, J. (1999). Neutral density revisited. Deep-Sea Research II, 46, $33-54$.

Ezer, T., \& Mellor, G. L. (1997). Simulations of the Atlantic Ocean with a free surface sigmacoordinate ocean model. Journal of Geophysical Research, 102, 15647-15657.

Gargett, A. E. (1984). Vertical eddy diffusivity in the ocean interior. Journal of Marine Research, 42, $359-393$.

Gent, P. R., \& McWilliams, J. C. (1990). Isopycnal mixing in ocean circualtion models. Journal of Physical Oceanography, 20, 150-155.

Gent, P. R., Willebrand, J., McDougall, T. J., \& McWilliams, J. C. (1995). Parameterizing eddy-induced tracer transports in ocean circulation models. Journal of Physical Oceanography, 25, 463-474.

Gerdes, R., \& Köberle, C. (1995). On the influence of DSOW in a numerical model of the North Atlantic general circulation. Journal of Physical Oceanography, 25, 2624-2642.

Haidvogel, D. B., Wilkin, J. L., \& Young, R. E. (1991). A semi-spectral primitive equation ocean circulation model using vertical sigma and orthogonal curvilinear coordinates. Journal of Computational Physics, 94, 151-185.

Hall, M., \& Bryden, H. (1982). Direct estimates of ocean heat transport. Deep-Sea Research, 29, 339-359.

Hasse, L., Lindau, R., Ruprecht, E. (1996). Climatological fluxes at the sea surface. In W. Krauss, The warmwatersphere of the North Atlantic Ocean, Chapter 2 (pp. 444). Berlin, Stuttgart: Gebrüder Bornträger.

Heywood, K. J., McDonagh, E. L., \& White, M. A. (1994). Eddy kinetic energy of the North Atlantic subpolar gyre. Journal of Geophysical Research, 99, 22525-22539.

Hirst, A. C., Jackett, D. R., \& McDougall, T. J. (1996). The meridional overturning cells of a world ocean model in neutral density coordinates. Journal of Physical Oceanography, 26, 775-791.

Holland, W. R., \& Bryan, F. O. (1994). Modeling the wind and thermohaline circulation in the North Atlantic ocean. In P. Malanotte-Rizzoli, \& A. R. Robinson, Ocean processes in climate dynamics: global and Mediterranean examples (pp. 135-156). Netherlands: Kluwer Academic Publishers.

Jia, Y. (2000). The formation of an Azores Current due to Mediterranean overflow in a modelling study of the north Atlantic. Journal of Physical Oceanography, 30, 2342-2358.

Käse, R. H., \& Krauss, W. (1996). The Gulf Stream, the North Atlantic Current, and the origin of the Azores Current. In W. Krauss, The warmwatersphere of the North Atlantic Ocean (pp. 291-338). Berlin, Stuttgart: Gebrüder Bornträger.

Killworth, P. D. (1996). Time interpolation of forcing fields in ocean models. Journal of Physical Oceanography, 26, 136-143.

Killworth, P. D. (1999). Relaxation towards observations in level and isopycnic models. Journal of Atmospheric and Oceanic Technology, 16, 983-986. 
Killworth, P. D., Dieterich, C., Le Provost, C., Oschlies, A., \& Willebrand, J. (2001). Assimilation of altimetric data and mean sea surface height into an eddy-permitting model of the North Atlantic. Progress in Oceanography, 48, 313-335.

Killworth, P. D., \& Edwards, N. R. (1999). A turbulent bottom boundary layer code for use in numerical ocean models. Journal of Physical Oceanography, 29, 1221-1238.

Kondo, J. (1975). Air-sea bulk transfer coefficients in diabatic conditions. Boundary Layer Meteorology, 9, 91-112.

Knochel, H. (1998). Devéloppement et validation d'un modèle numerique à coordonnée sigma pour l'étude climatique de l'Atlantique Nord. Mécanique des milieux géophysiques et environnement. Thèse de l'Université J. Fourier, Grenoble, 210 pp.

Kraus, E. B., \& Turner, J. S. (1967). A one-dimensional model of the seasonal thermocline. II: The general theory and its consequences. Tellus, 19, 98-106.

Lavin, A., Bryden, H., \& Parilla, G. (1998). Meridional transport and heat flux variations in the subtropical North Atlantic. The Global Atmosphere and Ocean System, 6, 269-293.

Ledwell, J. R., Watson, A. J., \& Law, C. S. (1998). Mixing of a tracer in the pycnocline. Journal of Geophysical Research, 103, 21499-21530.

Lee, T. N., Johns, W., Zantopp, R., \& Fillenbaum, E. (1996). Moored observations of western boundary current variability and thermohaline circulation at $26.5 \mathrm{~N}$ in the subtropical North Atlantic. Journal of Physical Oceanography, 26, 962-983.

Levitus, S. (1982). Climatological atlas of the world ocean. NOAA Professional Paper, 13, 173 pp. US Department of Commerce, National Oceanic and Atmospheric Administration.

Macdonald, A. M. (1998). The global ocean circulation: a hydrographic estimate and regional analysis. Progress in Oceanography, 41, 281-382.

Macdonald, A. M., \& Wunsch, C. (1996). An estimate of global ocean circulation and heat fluxes. Nature, London, 382, 436-439.

Marsh, R., Nurser, A. J. G., Megann, A. P., \& New, A. L. (2000). Water mass transformation in the Southern Ocean of a global isopycnal coordinate GCM. Journal of Physical Oceanography, 30, 1013-1045.

Marsh, R., Roberts, M. J., Wood, R. A., \& New, A. L. (1996). An intercomparison of a Bryan-Cox-type ocean model and an isopycnic ocean model. Part II: the subtropical gyre and meridional heat transport. Journal of Physical Oceanography, 26, 1528-1551.

McCartney, M. S., \& Curry, R. (1993). Transequatorial flow of Antarctic Bottom Water in the Western Atlantic Ocean: abyssal geostrophy at the Equator. Journal of Physical Oceanography, 23, 1264-1276.

McCartney, M. S., \& Talley, L. D. (1982). The subpolar mode water of the North Atlantic Ocean. Journal of Physical Oceanography, 12, 1169-1188.

McDougall, T. J., \& Dewar, W. K. (1998). Vertical mixing and cabbeling in layered models. Journal of Physical Oceanography, 28, 1458-1480.

McWilliams, J. C. (1996). Modeling the oceanic general circulation. Annual Review of Fluid Mechanics, 28, 215-248.

de Miranda, A. P., Barnier, B., \& Dewar, W. K. (1999). On the dynamics of the Zapiola Anticyclone. Journal of Geophysical Research, 104, 21137-21149.

New, A. L., Jia, Y., Coulibaly, M., \& Dengg, J. (2001). On the role of the Azores Current in the ventilation of the North Atlantic Ocean. Progress in Oceanography, 48, 163-194.

Oberhuber, J. (1993). Simulation of the Atlantic circulation with a coupled sea ice-mixed layer-isopycnal general circulation model. Part I: model description. Journal of Physical Oceanography, 23, 808-829.

Pacanowski, R. C. P. (1995). MOM 2 Documentation, User's Guide and Reference Manual. GFDL Ocean Technical Report 3, Princeton, N3, 232 pp.

Polzin, K. L., Toole, J. M., Ledwell, G. R., \& Schmitt, R. W. (1997). Spatial variability of turbulent mixing in the abyssal ocean. Science, 276, 93-96.

Redler, R., \& Böning, C. W. (1997). Effect of the overflows on the circulation in the subpolar North Atlantic: a regional model study. Journal of Geophysical Research, 102, 18529-18552.

Redler, R., \& Böning, C. W. (1997). Effect of the overflows on the circulation in the subpolar North Atlantic: a regional model study. Journal of Geophysical Research, 102, 18529-18552.

Rintoul, S. R., \& Wunsch, C. (1991). Mass, heat, oxygen and nutrient fluxes and budgets in the North Atlantic Ocean. Deep-Sea Research, 38, 355-377. 
Roberts, M. J., Marsh, R., New, A. L., \& Wood, R. A. (1996). An intercomparison of a Bryan-Cox-type ocean model and an isopycnic ocean model. Part I: the subpolar gyre and high-latitude processes. Journal of Physical Oceanography, 26, 1495-1527.

Roemmich, D., \& Wunsch, C. (1985). Two transatlantic sections: meridional circulation and heat flux in the subtropical North Atlantic Ocean. Deep-Sea Research, 33, 619-664.

Roemmich, D., \& Wunsch, C. (1985). Two transatlantic sections: meridional circulation and heat flux in the subtropical North Atlantic Ocean. Deep-Sea Research, 33, 619-664.

Rossby, T. (1996). The North Atlantic Current and surrounding waters, at the crossroad. Review of Geophysics, 34, $463-481$.

Sarmiento, J. L. (1986). On the North and tropical Atlantic heat balance. Journal of Geophysical Research, 91, $11677-11689$.

Schmitz, W. J. Jr., \& McCartney, M. S. (1993). On the North Atlantic circulation. Review of Geophysics, 31, $29-49$.

Schott, F. A., \& Molinari, R. L. (1996). The Western Boundary circulation of the subtropical warmwatersphere. In W. Krauss, The warmwatersphere of the North Atlantic Ocean (pp. 229-252). Berlin, Stuttgart: Gebrüder Bornträger.

Siefridt, L. (1994). Validation des données ERS-1 et des flux de surface du CEPMMT dans le contexte de la modélisation des circulations océaniques á l'échelle d'un bassin. These de Doctorat de l'Université Joseph Fourier, Grenoble I.

Singh, S., Kelly, K. A. (1997). Monthly maps of sea surface height in the North Atlantic and zonal indices for the Gulf Stream using TOPEX/Poseidon altimeter data. Woods Hole Oceanographic Institution Technical Report, WHOI-9706, pp. 50.

Smagorinsky, J. S. (1963). General circulation experiments with the primitive equations. I: The basic experiment. Monthly Weather Review, 91, 99-164.

Song, Y., \& Haidvogel, D. B. (1994). A semi-implicit ocean circulation model using a generalized topography following coordinate system. Journal of Computational Physics, 115, 228-244.

Speer, K., \& Zenk, W. (1993). The flow of Antarctic Bottom Water into the Brazil Basin. Journal of Physical Oceanography, 12, 2667-2682.

Stammer, D., Tokmakian, R., Semtner, A., \& Wunsch, C. (1996). How well does a $1 / 4^{\circ}$ global circulation model simulate large-scale oceanic observations? Journal of Geophysical Research, 101, 25779-25812.

Sun, S., Bleck, R., Rooth, C. G., Dukowicz, J., Chassignet, E. P., \& Killworth, P. D. (1999). Note on the inclusion of thermobaricity in numerical ocean models framed in isopycnic coordinates. Journal of Physical Oceanography, 29, 2719-2720.

Treguier, A. M. (1992). Kinetic energy analysis of an eddy resolving primitive equation model of the North Atlantic. Journal of Geophysical Research, 97, 687-701. 